\title{
Relationships Between Empirical Damage and Direct/Indirect Costs for the Assessment of Seismic Loss Scenarios
}

\author{
Marco Di Ludovico ( $\nabla$ diludovi@unina.it) \\ Giuseppina De MArtino \\ Università degli Studi di Napoli "Federico II" \\ Andrea Prota \\ Università degli Studi di Napoli "Federico II" \\ Gaetano Manfredi \\ Università degli Studi di Napoli "Federico II" \\ Mauro Dolce \\ Presidency of Council of Ministers
}

Università degli Studi di Napoli “Federico II" https://orcid.org/0000-0003-3697-3923

\section{Research Article}

Keywords: repair costs, population assistance costs, direct and indirect costs, empirical damage, usability rating, damage states, post-earthquake reconstruction process, loss scenarios.

Posted Date: June 17th, 2021

DOI: https://doi.org/10.21203/rs.3.rs-603444/v1

License: (1) This work is licensed under a Creative Commons Attribution 4.0 International License. Read Full License

Version of Record: A version of this preprint was published at Bulletin of Earthquake Engineering on October 5th, 2021. See the published version at https://doi.org/10.1007/s10518-021-01235-5. 


\title{
Relationships between empirical damage and direct/indirect costs for the assessment of seismic loss scenarios
}

\author{
Marco Di Ludovico ${ }^{\mathrm{a}}$, Giuseppina De Martino ${ }^{\mathrm{a}}$, Andrea Prota ${ }^{\mathrm{a}}$, Gaetano Manfredia ${ }^{\mathrm{a}}$, Mauro Dolce ${ }^{\mathrm{b}}$ \\ ${ }^{a}$ Università degli Studi di Napoli "Federico II", Via Claudio 21, 80125, Napoli, Italia \\ ${ }^{b}$ Civil Protection Department, Presidency of Council of Ministers, Rome, Italy
}

\begin{abstract}
The definition of relationships between damage and losses is a crucial aspect for the prediction of seismic effects and the development of reliable models to define risk maps, loss scenarios and mitigation strategies. The paper focuses on the analysis of post-earthquake empirical data to define relationships between buildings' damage expressed as usability rating or as global damage state and the associated costs for repair (i.e. direct costs) or for population assistance (i.e. a part of total indirect costs). The analysis refers to the data collected on residential buildings damaged by 2009 L'Aquila earthquake. For different usability rating or damage states, the paper presents the costs expressed in terms of percentage with respect to the reference unit cost of a new building ( $\% C_{r}$ and $\% C_{a}$ for repair and population assistance costs, respectively). In particular, the costs analysis refers to undamaged, lightly or severely damaged buildings classified according to usability rating (i.e. A, B$\mathrm{C}$ or E according to Italian classification) or to five different global Damage States (DSs). DSs comply with European Macroseismic Scale (EMS-98) and derive from literature available matrices properly defined to convert empirical damage to structural and non-structural components into building global damage. The $\% C_{r}$ probability density functions and relevant statistics derive from the analysis of actual data of post-earthquake reconstruction process, while, to determine those related to $\% C_{a}$, a deep analysis of population assistance types, person/month assistance cost for each assistance form, and a methodology to associate such costs to each building are herein presented and discussed. Finally the paper presents a relationship calibrated on empirical data to directly correlate repair costs on a building with assistance costs to their occupants.

The relationships between empirical damage and direct and indirect costs herein presented are of paramount importance because they allow reliable loss scenarios to be defined by simply using literature fragility curves (defined according to empirical or mechanical approaches) aimed at evaluating the probability of exceeding different usability rating or damage states of existing buildings.
\end{abstract}

Keywords: repair costs, population assistance costs, direct and indirect costs, empirical damage, usability rating, damage states, post-earthquake reconstruction process; loss scenarios.

\section{INTRODUCTION}

The assessment of seismic risk maps at a national scale is a crucial tool for investigating potential losses due to earthquakes in a region and for programming and introducing appropriate mitigation policies. In last twenty years, there has been a worldwide growing interest in developing seismic maps (RISK-UE (20012004), Zuccaro 2004, Lagomarsino and Giovinazzi 2006, Pitilakis et al. 2006, Shakib et al. 2011, Silva et al. 2015, Chaulagain et al. 2015, NDCP, ed., 2018, Silva et al. 2019, Dolce et al. 2020). To this aim, the combination of data coming from seismic hazard, structural vulnerability and exposure is needed; in particular, the definition of building vulnerability classes and relevant fragility curves to derive potential damage levels at a given earthquake intensity is crucial to assess reliable prediction of losses. Several seismic intensity measures have been used in recent years for characterization of seismic hazard: macro-seismic intensity scales; Peak Ground motion Acceleration, PGA, Velocity (PGV), Displacement (PGD), or spectral acceleration (Spence et al. 1992, M.W. Musson 2000, Rossetto T. 2014,). Fragility curves may be determined by means of different approaches, based on the observed data occurred in past seismic events (i.e. empirical approach, Braga et al. 1982, Rossetto and Elnasjai 2003, Rota et al. 2008, Zuccaro and Cacace 2015, Del Gaudio et al. 
2017, Rosti et al. 2018, Del Gaudio et al. 2019, Gaudio et al. 2020, Rosti et al. 2020) or on the assessment of damage predicted by buildings' modelling (i.e. analytical approach, Rossetto and Elnashai 2005, Lagomarsino and Giovinazzi 2006, Borzi et al. 2008, Rota et al. 2010,)

Then, the assessment of risk is not only affected by uncertainties related to fragility curves, but it is strongly correlated to the definition of suitable damage thresholds (empirically or mechanically based) and their correlation with losses. The correlation in terms of direct and indirect economic losses is a challenging task (Guha-Saphir D and Santos I. 2013), especially for what concern indirect losses that are not straightforwardly expressed in monetary terms but can significantly impact on the Gross Local Product (GLP).

The current efforts of the scientific community aim at integrating risk maps with data related to economic losses intended as the sum of the direct costs necessary to repair the damage detected on buildings following a seismic event, and the associated indirect costs. The former may derive from the analysis of the most recent cost data for the reconstruction of areas affected by the earthquake. As far as indirect costs are concerned, the assistance costs to the population certainly represents a significant ratio of losses (Mannella et al., 2017) in addition to those due to the interruption of economic activity and the reduction of production in the industrial sector (Benson and Clay, 2004).

The present study aims at investigating direct and indirect costs by analysing data related to the reconstruction process of reinforced concrete (RC) and masonry residential buildings damaged by L'Aquila 2009 earthquake (Di Ludovico et al. 2017a,b). In particular, the direct costs are analysed as a function of different parameters representative of the building damage: usability rating (i.e. usable, unusable with light damage, unusable with severe damage); reconstruction class (i.e. light reconstruction and heavy reconstruction); and global damage state (DS) defined trough different conversion matrices on the basis of empirical damage observed on structural and non-structural components. Indirect costs in the form of assistance population costs are also associated to buildings by analysing the costs related to financial assistance for accommodation in tents, hotels, self-accommodations (so-called "self-accommodation grant, s.a.g.") or structures intended to outlast the recovery timeframe (i.e. M.A.P., Temporary Inhabitable Modules, or the socalled "C.A.S.E. project", Anti-seismic, Sustainable and Ecologically Compatible Housing Complexes). The costs of each assistance form are computed for each person, associated to buildings' occupants, and analysed for different levels of buildings' empirical damage.

The usability assessment aims at evaluating the safety conditions of the buildings and the actions required to enable people to return to their houses The data herein analysed refers to usability assessment of buildings according to Italian classification based on the AeDES survey form (Baggio et. al. 2007). However, the study can be easily extended to other seismic prone countries, which commonly adopt similar forms aimed at the final evaluation of usability categories (e.g. Japan, Goretti and Inukai 2002; U.S., ATC, 2005; New Zealand, NZSEE, 2009). For example, according to ATC, 2005, a building is tagged "Green" for unrestricted access, "Yellow", for restricted access, and "Red" for no access, while the AeDES form leads to six usability categories: A. Usable buildings; B. Building usable only after short term countermeasures; C. Partially usable building; D. Building to be re-inspected; E. Unusable building; F. Unusable building for external risk.

The correlation between usability rating and costs is particularly valuable to quickly predict losses in the immediate post-earthquake because the usability rating of buildings is generally evaluated in the initial emergency stages. It also provides the opportunity to predict the ratio of indirect losses related to population assistance; indeed, population assistance costs are strictly correlated to the housing recovery time that mostly depends on usability rating. Thus, relationships between usability rating and direct and indirect costs are crucial to those involved in the post-emergency reconstruction phases management because they may give the opportunity to plan an overall economic development plan. However, the risk assessment in "peace time", starting from models based on the usability rating and relevant reconstruction phases prediction is not easily feasible because reliable models to predict the usability rating of buildings are still lacking.

Thus, the costs data associated to building global damage levels are certainly more appropriate for the definition of loss scenarios in "peace-time". In such a case, once a seismic input scenario is assumed in a given area, with known exposure data, the number of buildings attaining different DSs can be evaluated based on the use of empirical or mechanically based fragility curves; then, the losses can be immediately assessed if association between DS and costs are available. This is a critical issue because significant uncertainties are related to the capability of DSs to take into account not only the damage level but also its extent and diffusion, as well as its incidence on repair costs actions (De Martino et al. 2017, Del Vecchio et al. 2018, Del Vecchio et al. 2020). Different conversion matrices from empirical damage detected on RC and masonry buildings to 
building DSs are herein investigated along with the dispersion in terms of predicted costs (both in terms of repair costs and assistance to population costs). Although affected by uncertainties, these data may be essential to define loss scenarios and consequently to drive decisions makers involved in the definition and planning of suitable seismic risk mitigation policies (Cosenza et. al. 2018).

\section{DATABASE FOR THE ANALYSIS: L'AQUILA 2009 POST EARTHQUAKE}

The reconstruction process following L'Aquila 2009 earthquake allowed collecting data on 5,775 residential damaged buildings outside historical centres: $49 \%$ reinforced concrete buildings, $46 \%$ masonry buildings, and 5\% other types such as mixed, steel etc. (Di Ludovico et al. 2017a,b).

The present study focuses on a significantly enlarged database made of 8,497 residential buildings, which comprises also data on usable buildings outside historical centres (i.e. A rating according to AeDES form), see Table 1. In particular, it refers to 4,995 usable buildings and 3,502 unusable ones (out of the 5,775 analysed in Di Ludovico et al. 2017a,b). This because on 4,995 usable buildings (2,421 RC and 2,574 masonry buildings) and 3,502 unusable ones (2,243 RC and 1,259 masonry buildings) it was possible to derive all the information needed for the study: damage on structural and non-structural components; repair intervention costs computed by practitioners engaged by property owners to apply for public grant for reconstruction, as regulated by OPCM no. 3778, OPCM no. 3779, OPCM no. 3790, and OPCM no. 3881 (namely "direct" costs in the following); buildings' recovery time and costs for occupants' assistance (namely "indirect" costs in the following, even if they represents only a part of total indirect costs).

The data on building types and damage resulted from the usability assessment surveys carried out in the immediate post-earthquake by using the AeDES form (Baggio et. al. 2007). They refer to different usability rating: A rating, 4,995 undamaged buildings corresponding to 59\% of the database; $\mathrm{B}$ or $\mathrm{C}$ ratings (B-C in the following), 2,180 lightly damaged buildings corresponding to $25 \%$ of the database; E rating, 1,322 severely damaged building corresponding to $16 \%$ of the database, see Table 1.

For the post-earthquake reconstruction, fully coverage of repair costs was guaranteed by the Italian government with a fixed upper bound per dwelling and per common areas of condominiums in case of A rating (Dolce and Manfredi 2015); economic convenience limits were foreseen in case of B-C or E rating buildings (see (Di Ludovico et al. 2017b). The reconstruction process of B-C buildings ("light damage" reconstruction) started before that related to E ones ("'heavy damage" reconstruction) to enable rapid re-occupancy of slightly damaged buildings, thus reducing public costs incurred for homeless housing assistance. Moreover, in the reconstruction process, E-rating buildings were further classified in sub-classes: class E-B, including buildings with a high non-structural damage but with slight structural damage; $\mathrm{E}_{\text {class }}$ including buildings with severe structural damage, and $\mathrm{E}_{\mathrm{dem}}$, including buildings that needed to be demolished. In the E-B class of buildings, a faster local strengthening strategy was mostly selected to overcome the structural weaknesses. By contrast, in the class $E_{\text {dem }}$ demolition was selected as the most viable solution because of strong structural weaknesses, a high residual drift, local or global collapse, or excessive costs of repair/retrofit interventions compared to the costs of demolition and reconstruction (Di Ludovico et al. 2017b). Table 1 summarizes the number of buildings, RC or masonry ones, in each class.

Table 1. Database.

\begin{tabular}{cccc}
\hline $\begin{array}{c}\text { Usability } \\
\text { rating }\end{array}$ & $\begin{array}{c}\text { Reconstruction } \\
\text { class }\end{array}$ & $\begin{array}{c}\text { Building } \\
\text { type }\end{array}$ & $\begin{array}{c}\text { No. of } \\
\text { buildings }\end{array}$ \\
\hline \multirow{3}{*}{ A } & A & RC & 2,421 \\
& & Masonry & 2,574 \\
& & Total & 4,995 \\
\hline \multirow{3}{*}{ B-C } & \multirow{2}{*}{ B-C } & RC & 1,402 \\
& & Masonry & 778 \\
& & Total & 2,180 \\
\hline \multirow{3}{*}{ E-B } & RC & 183 \\
& & Masonry & 30 \\
& & Total & 213 \\
\hline \multirow{3}{*}{ E } & \multirow{3}{*}{ EClass } & Masonry & 420 \\
& & Total & 277 \\
& \multirow{3}{*}{ Edem } & RC & 238 \\
& & Masonry & 174 \\
& & Total & 412 \\
\hline
\end{tabular}


Starting from such buildings' database, a further classification is herein assumed based on the empirical damage detected in the "Section 4 - Damage to the structural components" of the AeDES form. This section identifies four damage grades (D0-no damage, D1, slight damage; D2-D3 medium-severe damage; D4-D5 very heavy damage or collapse) and relevant extent for structural and non-structural members (i.e. Vertical Structures, VS, Floors, $F$, Stairs, $S$, Roofs, $R$, and Infills-Partitions, $I P$ ). The empirical damage data have been elaborated in order to derive, for each building, a global Damage State, DS, according to the European Macroseismic Scale EMS-98 (Grunthal 1998). The conversion matrix reported in Del Gaudio et al 2019 is used to define DS of RC buildings, while that one reported in Dolce et al., 2019 is used for masonry buildings; the former takes into accounts the maximum severity of the damage detected on VS and IP to derive DS, while the latter only refers to damage to VS in terms of both severity and relevant extent.

Figure 1 shows the distributions of the number of RC (a) and masonry (b) buildings as a function of DS for the buildings' database. A peak of 1,835 buildings in DS1 and 2,151 in DS0 is observed for RC and masonry buildings, respectively.

4,664 RC BUILDINGS

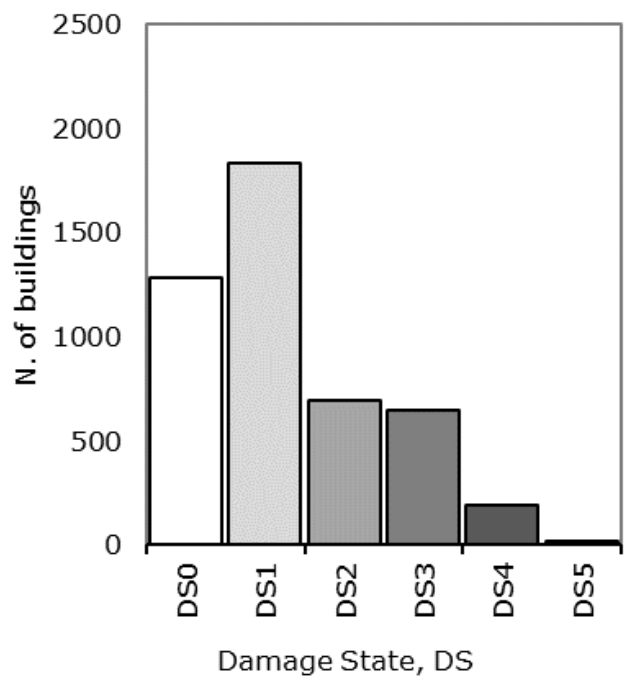

(a)

\section{3,833 MASONRY BUILDINGS}

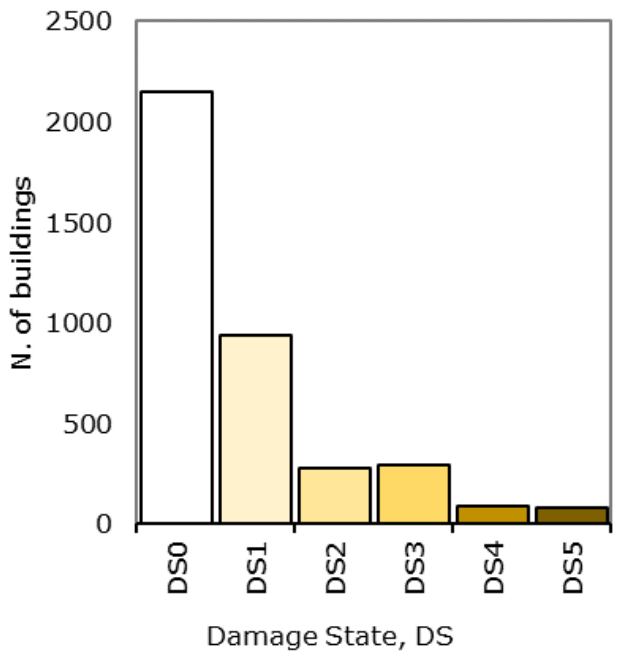

(b)

Figure 1. Number of buildings for each DS defined according to Del Gaudio et al, 2019 for RC buildings (a) and to Dolce et al, 2019 for masonry buildings (b)

Table 2 and Table 3 summarize the DS distributions as a function of usability ratings and reconstruction classes of RC and masonry buildings, respectively. As expected, the data shows that the higher the DS, the lower is the percentage ratio of $\mathrm{A}$ and $\mathrm{B}-\mathrm{C}$ buildings.

The number of A rating buildings is null for DS greater than DS2: DS0 is the most populated group, $49 \%$ and $76 \%$ for RC and masonry buildings, respectively. Because damage to $I P$ is taken into account in the conversion matrix of RC buildings, DS1 is also significantly populated, $48 \%$.

The B-C rating buildings mostly belong to DS1 or DS2 (i.e. $45 \%$ and $36 \%$ for RC buildings, and $42 \%$ and $26 \%$ for masonry ones). In case of E rating buildings, DS3 is the most populated class: $56 \%$ for RC buildings, and $46 \%$ for masonry buildings.

Reconstruction class $E_{\text {dem }}$ should be analysed to derive peak values of DS4 and DS5; in particular, the peak percentage of DS4, 38\%, refers to RC buildings, and the peak percentage of DS5, 29\%, refers to masonry buildings. The data reported in

Table 2 and Table 3 could be very useful to define simple correlations between a single parameter defining the building global damage, that is DS, to a rating defining the usability of buildings in the earthquakes aftermath.

Table 2. The DS distribution as a function of usability ratings and reconstruction classes: RC buildings 


\begin{tabular}{|l|c|c|c|}
\hline & \multicolumn{3}{|c|}{$\begin{array}{c}\text { Usability } \\
\text { rating }\end{array}$} \\
\hline Damage states & A & B-C & E \\
\hline DS0 & $49 \%$ & $7 \%$ & $0 \%$ \\
\hline DS1 & $48 \%$ & $45 \%$ & $3 \%$ \\
\hline DS2 & $2 \%$ & $36 \%$ & $15 \%$ \\
\hline DS3 & $0 \%$ & $12 \%$ & $56 \%$ \\
\hline DS4 & $0 \%$ & $0 \%$ & $23 \%$ \\
\hline DS5 & $0 \%$ & $0 \%$ & $2 \%$ \\
\hline
\end{tabular}

\begin{tabular}{|c|c|c|}
\hline \multicolumn{3}{|c|}{$\begin{array}{c}\text { Reconstruction } \\
\text { classes }\end{array}$} \\
\hline E-B & E $_{\text {class }}$ & Edem \\
\hline $0 \%$ & $0 \%$ & $0 \%$ \\
\hline $3 \%$ & $2 \%$ & $5 \%$ \\
\hline $26 \%$ & $14 \%$ & $9 \%$ \\
\hline $60 \%$ & $62 \%$ & $42 \%$ \\
\hline $11 \%$ & $20 \%$ & $38 \%$ \\
\hline $0 \%$ & $2 \%$ & $5 \%$ \\
\hline
\end{tabular}

Table 3. The DS distribution as a function of usability ratings and reconstruction classes: masonry buildings

\begin{tabular}{|l|c|c|c|}
\hline & \multicolumn{3}{|c|}{ Usability rating } \\
\hline Damage states & A & B-C & E \\
\hline DS0 & $76 \%$ & $23 \%$ & $2 \%$ \\
\hline DS1 & $23 \%$ & $42 \%$ & $4 \%$ \\
\hline DS2 & $1 \%$ & $26 \%$ & $12 \%$ \\
\hline DS3 & $0 \%$ & $9 \%$ & $46 \%$ \\
\hline DS4 & $0 \%$ & $0 \%$ & $19 \%$ \\
\hline DS5 & $0 \%$ & $0 \%$ & $17 \%$ \\
\hline
\end{tabular}

\begin{tabular}{|c|c|c|}
\hline \multicolumn{3}{|c|}{$\begin{array}{c}\text { Reconstruction } \\
\text { classes }\end{array}$} \\
\hline E-B & E & Edem \\
\hline $7 \%$ & $3 \%$ & $0 \%$ \\
\hline $13 \%$ & $6 \%$ & $0 \%$ \\
\hline $20 \%$ & $14 \%$ & $7 \%$ \\
\hline $47 \%$ & $51 \%$ & $40 \%$ \\
\hline $13 \%$ & $16 \%$ & $24 \%$ \\
\hline $0 \%$ & $11 \%$ & $29 \%$ \\
\hline
\end{tabular}

\section{REPAIR COSTS}

The section focuses on the analysis of actual repair costs (i.e. direct costs) related to buildings with different level of damage expressed in terms of: i) usability rating, A, B-C, E (and relevant reconstruction classes, E-B, $\left.\mathrm{E}_{\text {class }}, \mathrm{E}_{\mathrm{dem}}\right)$; ii) or global damage, DS.

The actual repair costs have been computed by practitioners involved in the post L'Aquila earthquake reconstruction process; they represent the costs to restore the original conditions of structural or non-structural elements of buildings damaged by the earthquake. They are inclusive of charges for the design and technical assistance of practitioners while they are not inclusive of VAT. The actual costs herein analysed are normalized by the overall building gross surface area (i.e. $€ / \mathrm{m}^{2}$ ); furthermore, in the following, they are expressed as a percentage cost, $\% C_{r}$, with respect to reference unit cost of a building (i.e. CU, assumed equal to $1.350 € / \mathrm{m}^{2}$ including technical expenses and VAT, NDCP, ed., 2018).

\subsection{Usability rating}

Table 4 summarizes the percentage costs of repair, $\% \mathrm{C}_{\mathrm{r}}$, computed for $\mathrm{A}, \mathrm{B}-\mathrm{C}$ and $\mathrm{E}$ usability rating buildings; the median, $16^{\text {th }}, 84^{\text {th }}$ percentile, mean, standard deviation and $\mathrm{CoV}$ are also reported.

Table $4 . \% \mathrm{C}_{\mathrm{r}}$ as a function of usability rating.

\begin{tabular}{|c|c|c|c|c|c|c|}
\hline & \multicolumn{3}{|c|}{$\mathrm{RC}$ buildings } & \multicolumn{3}{|c|}{ Masonry buildings } \\
\hline Usability rating & $\mathbf{A}$ & B-C & $\mathrm{E}$ & $\mathbf{A}$ & B-C & E \\
\hline No. of buildings & 2,421 & 1,402 & 841 & 2,574 & 778 & 481 \\
\hline$\% C_{r}-16^{\text {th }}$ percentile & $0 \%$ & $6 \%$ & $24 \%$ & $0 \%$ & $7 \%$ & $23 \%$ \\
\hline$\% C_{r}$ - median & $0 \%$ & $12 \%$ & $43 \%$ & $0 \%$ & $14 \%$ & $42 \%$ \\
\hline$\% C_{r}-84^{\text {th }}$ percentile & $4 \%$ & $22 \%$ & $87 \%$ & $5 \%$ & $25 \%$ & $86 \%$ \\
\hline$\% C_{r}$ mean & $2 \%$ & $14 \%$ & $51 \%$ & $2 \%$ & $16 \%$ & $52 \%$ \\
\hline$\% C_{r}$ standard deviation & $3 \%$ & $9 \%$ & $29 \%$ & $4 \%$ & $10 \%$ & $30 \%$ \\
\hline$\% C_{r} \mathrm{CoV}$ & $158 \%$ & $64 \%$ & $56 \%$ & $182 \%$ & $62 \%$ & $58 \%$ \\
\hline
\end{tabular}

Note that the repair costs are also associated to usable buildings (i.e A rating) for which public coverage of the limited damage was allowed according to OPCM no. 3778. In particular, OPCM no. 3778 established a maximum public grant for repair in case of A rating buildings equal to $10.000 €$ for each condominium unit or independent dwelling and a further contribution up to $2500 €$ for repair of common areas. For B-C and E rating buildings, no upper bound was defined for repair costs unless repair plus strengthening costs resulted greater than CU (i.e. economic convenience), OPCM no. 3790. The economic convenience limit was achieved only 
in case of $E$ rating buildings (i.e. $E_{\text {dem }}$ reconstruction class); in such a case the cost for reconstruction has been computed according to provision issued by the Resolution Regional Council DGR no. 615 form (2010) and resulted on average equal to about $1200 € / \mathrm{m}^{2}$. Table 4 shows that mean [median] values of $\% \mathrm{C}_{\mathrm{r}}$ resulted: $2 \%$ [0\%], 14\% [12\%] and 51\%[43\%] for A, B-C and E rating RC buildings, and 2\% [0\%], 16\% [14\%] and 52\% [42\%] for $\mathrm{A}, \mathrm{B}-\mathrm{C}$ and $\mathrm{E}$ rating masonry ones. The percentage costs of repair, $\% \mathrm{C}_{\mathrm{r}}$, related to $\mathrm{E}$ rating buildings are explored for different reconstruction classes $\left(\mathrm{E}-\mathrm{B}, \mathrm{E}_{\mathrm{class}}\right.$ and $\left.\mathrm{E}_{\mathrm{dem}}\right)$ in Table 5. It resulted that mean [median] $\% \mathrm{C}_{\mathrm{r}}$ decreases up to $26 \%$ [26\%] and 20\% [19\%] for RC and masonry E-B buildings while it attains $90 \%$ [88\%] and $87 \%$ [84\%] for $\mathrm{E}_{\mathrm{dem}}$ reconstruction class (with $84^{\text {th }}$ percentile greater than $100 \%$ in each case). Demolition and reconstruction resulted the most viable solution on about one third of $\mathrm{E}$ ratinig buildings. The mean $\% \mathrm{C}_{\mathrm{r}}$ for E-B RC buildings exceeds that one of masonry ones due the significant contribution of infills and partitions; indeed, in RC buildings, they are largely damaged and this imply significant repair actions and relevant costs. For the same reason, the coefficient of variations, $C o V$, of buildings with severe structural damage (i.e. E rating), were generally lower than the ones of buildings with light damage (i.e. B-C rating), see Table 4. This because the high variability of costs related to actions aimed at restoring damage on partitions and curtain walls, and in general on non-structural components (i.e. systems, fixtures, finishes, etc.).

Table $5 . \% \mathrm{C}_{\mathrm{r}}$ as a function of reconstruction class.

\begin{tabular}{|c|c|c|c|c|c|c|}
\hline & \multicolumn{3}{|c|}{$841 \mathrm{RC}$ buildings } & \multicolumn{3}{|c|}{481 Masonry buildings } \\
\hline Reconstruction class & E-B & $\mathrm{E}_{\text {class }}$ & Edem & E-B & $\mathbf{E}_{\text {class }}$ & Edem \\
\hline No. of buildings & 183 & 420 & 238 & 277 & 30 & 174 \\
\hline$\% C r-16^{\text {th }}$ percentile & $14 \%$ & $25 \%$ & $78 \%$ & $9 \%$ & $21 \%$ & $71 \%$ \\
\hline$\% \mathrm{Cr}$ - median & $26 \%$ & $39 \%$ & $88 \%$ & $19 \%$ & $33 \%$ & $84 \%$ \\
\hline$\% C r-84^{\text {th }}$ percentile & $36 \%$ & $53 \%$ & $103 \%$ & $29 \%$ & $47 \%$ & $102 \%$ \\
\hline$\% C r$ - mean & $26 \%$ & $39 \%$ & $90 \%$ & $20 \%$ & $34 \%$ & $87 \%$ \\
\hline$\% \mathrm{Cr}$ - standard deviation & $11 \%$ & $14 \%$ & $15 \%$ & $10 \%$ & $13 \%$ & $17 \%$ \\
\hline$\% \mathrm{Cr}-\mathrm{CoV}$ & $42 \%$ & $35 \%$ & $17 \%$ & $50 \%$ & $37 \%$ & $19 \%$ \\
\hline
\end{tabular}

The data reported in Table 4 (and Table 5) are crucial to quickly define loss scenarios in the post-earthquake phases once the usability rating of buildings in the struck area has been completed. However, in terms of predictions these data can be suitably adopted only if fragility curves, able to predict the probability of buildings exceeding given usability rating for a certain seismic intensity, are provided. These curves are generally lacking (Zucconi et al., 2018) because literature studies have been commonly focused on fragility curves expressed as a function of a parameter related to the building global damage, DS (NDCP, ed., 2018, Dolce et al., 2020). Although preliminary correlations between DS and usability rating are herein provided based on empirical data recorded in the post L'Aquila 2009 earthquake, to overcome such issue, a direct correlation between repair costs and DS is reported and discussed in detail in the following section.

\subsection{Damage State}

Table 7 summarizes the percentage costs of repair, $\% \mathrm{C}_{\mathrm{r}}$, computed for different damage states, $D S$; the median, $16^{\text {th }}, 84^{\text {th }}$ percentile, mean, standard deviation and $\mathrm{CoV}$ are also reported.

Table $6 . \% \mathrm{C}_{\mathrm{r}}$ as a function of damage states, DS.

\begin{tabular}{|c|c|c|c|c|c|c|c|c|c|c|}
\hline & \multicolumn{5}{|c|}{ 4,664 $\mathrm{RC}$ buildings } & \multicolumn{5}{|c|}{ 3,833 RC buildings } \\
\hline Damage States & DS1 & DS2 & DS3 & DS4 & DS5 & DS1 & DS2 & DS3 & DS4 & DS5 \\
\hline No. of buildings & 1,835 & 690 & 643 & 194 & 20 & 941 & 276 & 292 & 92 & 81 \\
\hline$\% C r-16^{\text {th }}$ percentile & $0 \%$ & $6 \%$ & $14 \%$ & $26 \%$ & $44 \%$ & $0 \%$ & $8 \%$ & $16 \%$ & $25 \%$ & $34 \%$ \\
\hline$\% C r$ - median & $3 \%$ & $14 \%$ & $34 \%$ & $59 \%$ & $81 \%$ & $4 \%$ & $17 \%$ & $33 \%$ & $52 \%$ & $72 \%$ \\
\hline$\% C r-84^{\text {th }}$ percentile & $13 \%$ & $29 \%$ & $64 \%$ & $95 \%$ & $107 \%$ & $17 \%$ & $35 \%$ & $78 \%$ & $96 \%$ & $95 \%$ \\
\hline$\% C r$ - mean & $6 \%$ & $19 \%$ & $39 \%$ & $62 \%$ & $78 \%$ & $8 \%$ & $22 \%$ & $41 \%$ & $59 \%$ & $67 \%$ \\
\hline$\% C r$ - standard d & $10 \%$ & $18 \%$ & $26 \%$ & $32 \%$ & $32 \%$ & $10 \%$ & $19 \%$ & $28 \%$ & $33 \%$ & $29 \%$ \\
\hline$\% C r-\mathrm{CoV}$ & $64 \%$ & $105 \%$ & $149 \%$ & $195 \%$ & $191 \%$ & $76 \%$ & $116 \%$ & $157 \%$ & $163 \%$ & $235 \%$ \\
\hline
\end{tabular}

Figure 2 shows the frequency distributions and the best fitting probability density function (PDF) of $\% \mathrm{C}_{\mathrm{r}}$ for RC (Figure 2a,c,e,g,i,m) and masonry buildings (Figure 2b,d,f,h,l,n), respectively; the cumulative distribution function $(\mathrm{CDF})$ of $\% \mathrm{C}_{\mathrm{r}}$ is also reported in each graph. 
For DS0 and DS1 a mixture distribution has been assumed in order to combine a discrete (degenerate distribution) and a continuous probability distribution (lognormal distribution); indeed, in such DSs a fixed probability value should be assigned to $\% \mathrm{C}_{\mathrm{r}}=0$ (e.g. $31 \%$ and $35 \%$ for $\mathrm{RC}$ and masonry buildings at DS0 and $4 \%$ for both buildings types at DS1) while for $\% \mathrm{C}_{\mathrm{r}}$ greater than 0 , a lognormal distribution approximates well the distribution of $\% \mathrm{C}_{\mathrm{r}}$. For DS3 and DS4 a mixture distribution of two lognormal distributions has been assumed in order to capture the trend of data that are affected by two different probability peaks. Indeed, severely damaged buildings mostly belongs to such DSs and, thus, if demolition resulted the most convenient solution, the $\% \mathrm{C}_{\mathrm{r}}$ values shifted to higher $\% \mathrm{C}_{\mathrm{r}}$ values with respect to $\% \mathrm{C}_{\mathrm{r}}$ related to repairable buildings. Fiinally for DS5 a normal distribution has been assumed for RC buildings to obtain the best fitting probability density function while a mixture of a normal and a lognormal distribution has been assumed for masonry buildings. Figures 2a,b,c,d,e,f also reports the PDF key parameters such as degenarete distribution $\mathrm{x}$ and $\mathrm{y}$ coordinates, the proportion parameter Pp in a mixture of distibutions, the median and scatter of lognormal distribution, $\mathrm{e}^{\mu}$ and $\mathrm{e}^{\sigma}$, as well as mean and standard deviation of normal distribution, $\mu$ and $\sigma$.

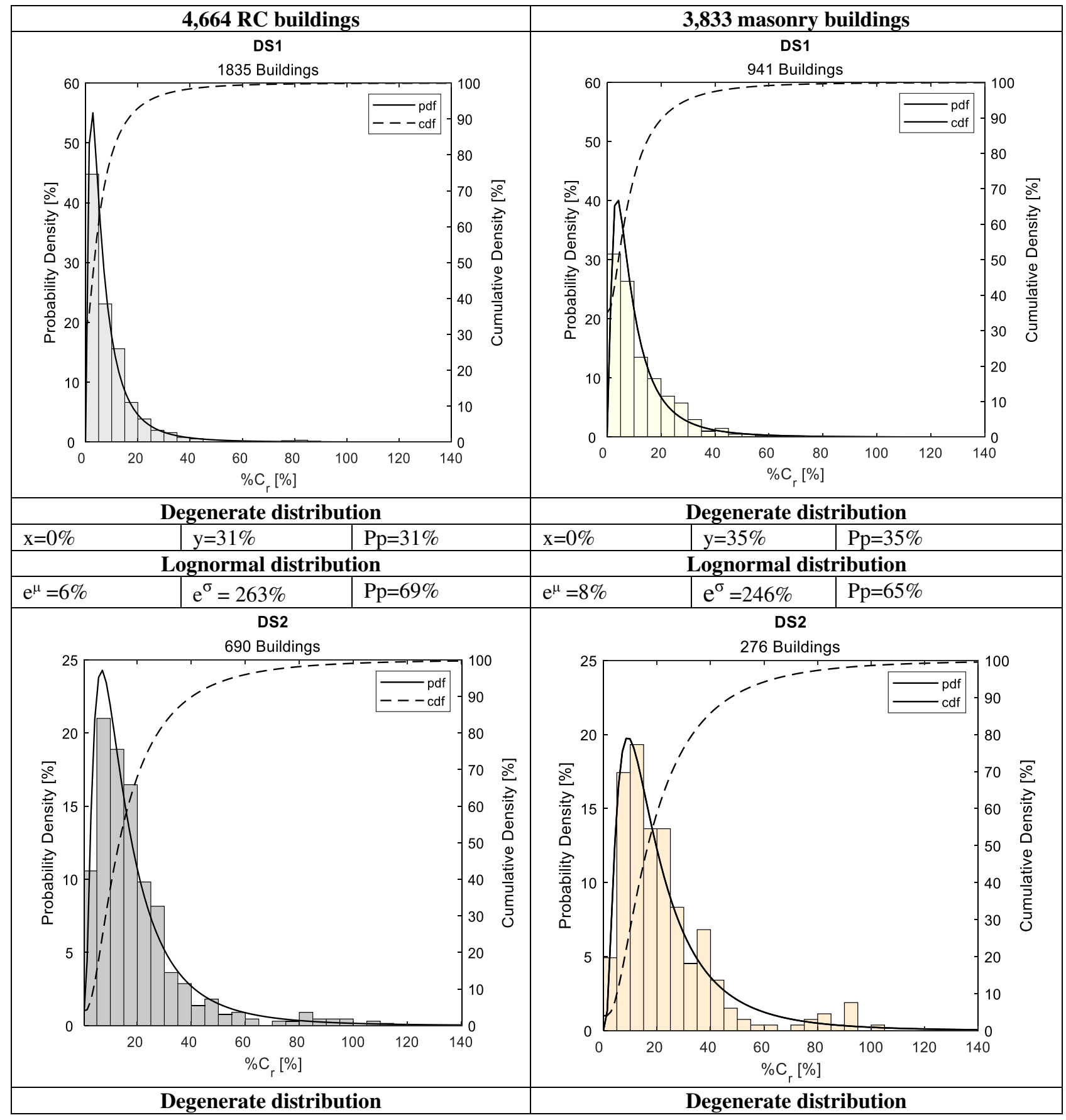




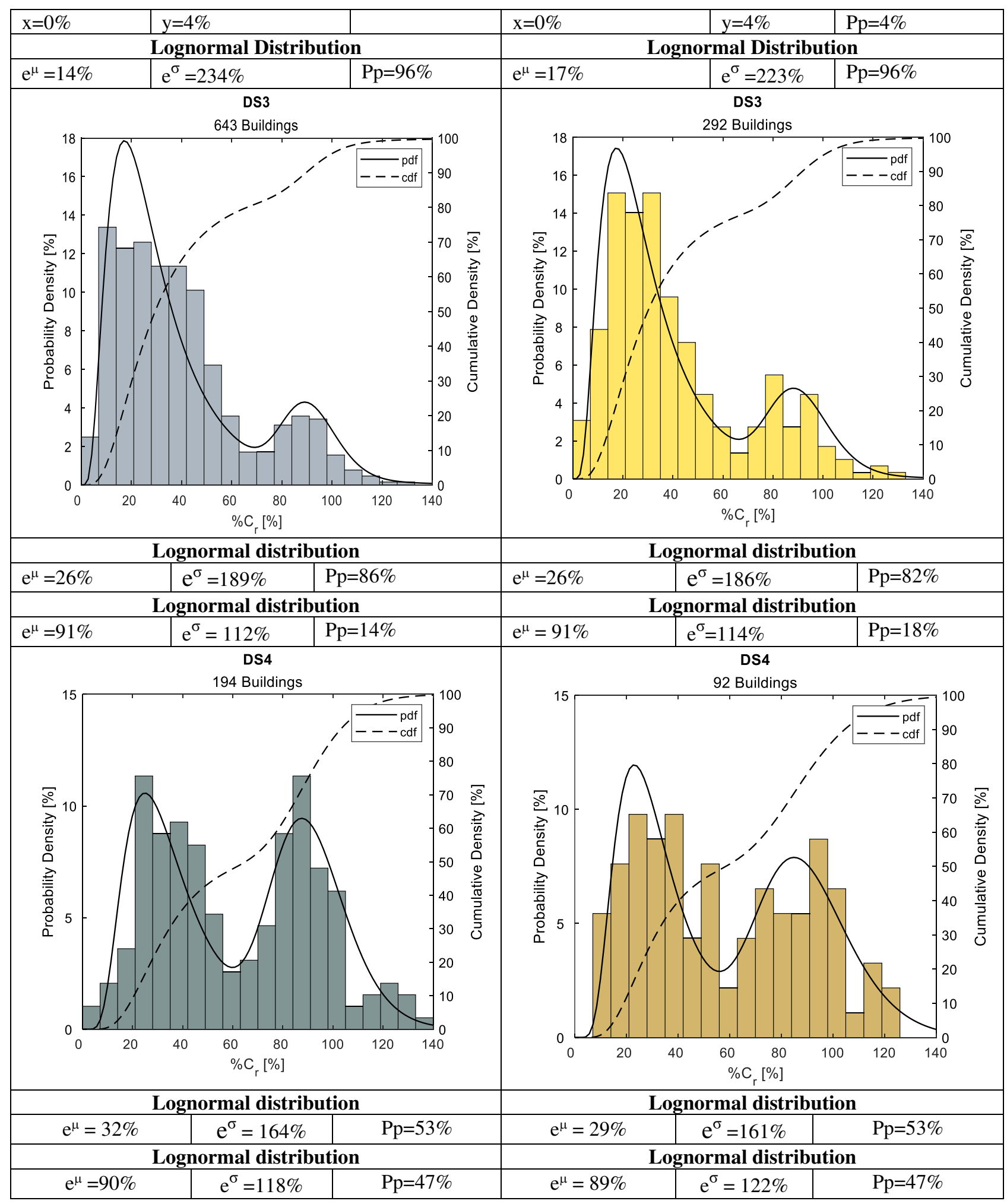




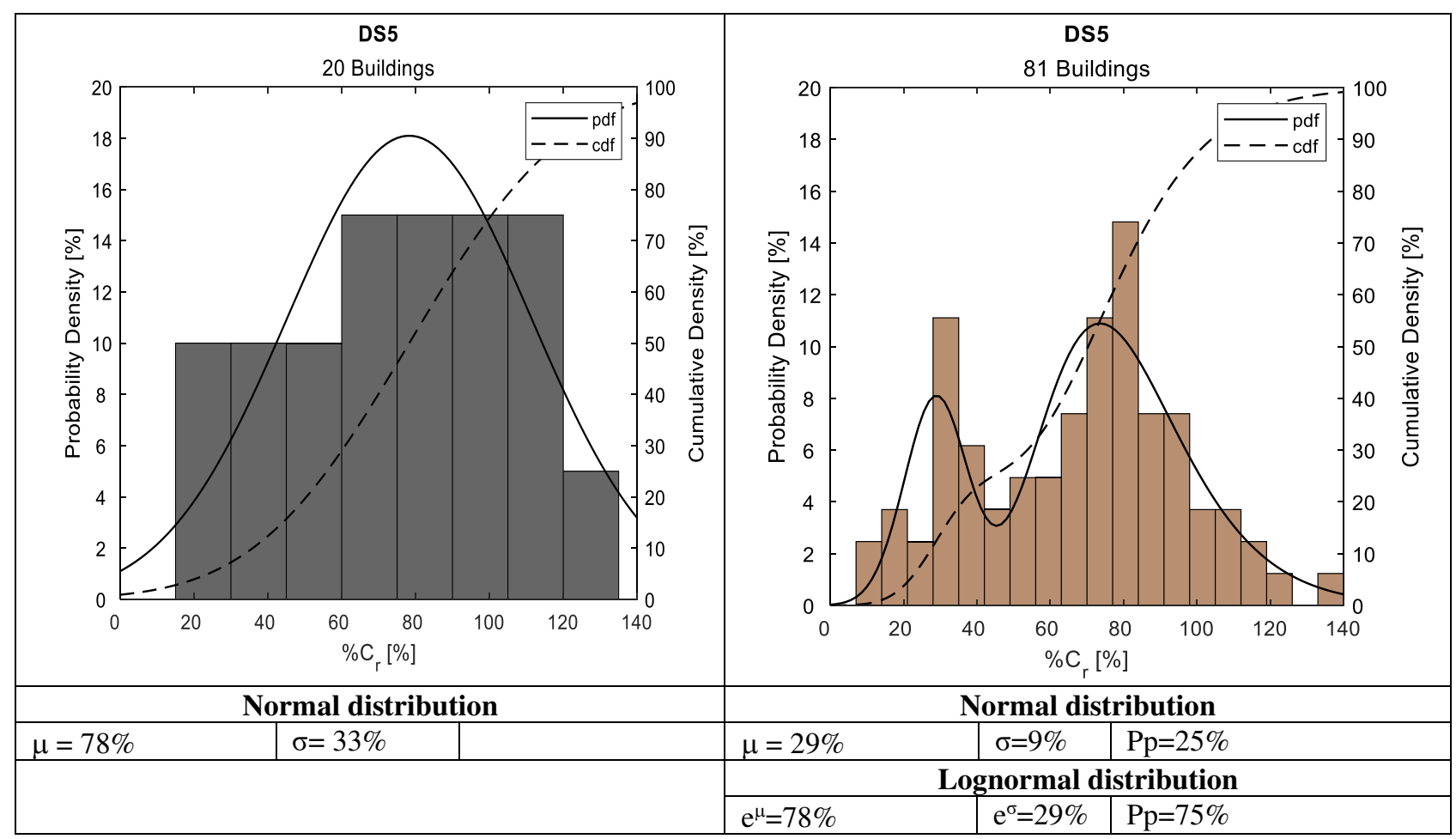

Figure 2. Frequency distribution of $\% C_{r}$ related to RC (a,c,e, g,i,m) and masonry (b,d,f,h,l,n) buildings at different damage states, $D S$.

\section{POPULATION ASSISTANCE COSTS}

The section focuses on the analysis of population assistance costs. They are a significant part of indirect costs in the post-earthquake recovery process. In the first emergency phase of 2009 L'Aquila earthquake, two different types of assistance to the population were provided: accommodation in tent camps set up by the Department of Civil Protection (DPC) and hospitality in hotels, mainly located on the Adriatic coast (about 70 $\mathrm{km}$ away from L'Aquila). In particular, 35,690 people were assisted in 5,957 tents of 171 camps and 33,964 people in hotels (Dolce, 2010a, Mannella et al., 2017), for a total of 69,654 people.

The huge number of displaced people highlighted the need to adopt several types of assistance to the population who lived in light or heavy damaged buildings: hotels; self-accommodation grant (namely s.a.g. in the following), traditional temporary wooden-house units, M.A.P. ("Temporary Inhabitable Modules"), and innovative high quality and comfort standards housing modules, so-called C.A.S.E. project ("Anti-seismic, Sustainable and Ecologically Compatible Housing Complexes"), (Dolce, 2010a). In the framework of the C.A.S.E. project 4,500 apartments located in 185 buildings were built with the capacity to accommodate a maximum of 15,000 people (DPC, 2018b). Temporary units, M.A.P., consisted of 3,166 wooden housing modules, out of which 1,113 for the districts of L'Aquila able to accommodate a maximum of 3,324 people (DPC, 2018), and 2,053 in the other municipalities. The construction of M.A.P modules and C.A.S.E. project started on June 2009 and ended in February 2010. The first apartments were delivered on September 2009.

The types of assistance have been used in a complementary and flexible manner taking into account the progress of demand (i.e. number of people needing assistance) and capacity (available housing accommodation in the temporary facilities, i.e. M.A.P. and C.A.S.E.). The usability rating of buildings also played a crucial role in the population assistance evolution because people living in severely damaged buildings were mainly hosted in M.A.P. and C.A.S.E.

In order to provide actual data on population assistance costs, a proper database has been developed in this study. It collects data on the number of assisted people for each month and each type of assistance and relevant costs; they derive from reports published by Deputy Commissioner for Reconstruction, Department of Civil Protection and the Special Offices for the Reconstruction of historical centres of L'Aquila (USRA, https://usra.it/) and the other municipalities (USRC, http://www.usrc.it/).

Figure 3 shows the number of assisted people per month for each type of assistance (i.e. tents, hotels, s.a.g., M.A.P., C.A.S.E.); the actual data refers to the period April 2009 - December 2018 but the graphs also reports 
the trends up to December 2024 which is the supposed end of the reconstruction process according to USRA and USRC source of data (month 1 - 189 in the graph). Indeed, according to the current trend of people returning home they suppose that the assistance to people will end in 2024, with a total duration of 15 years and half (189 months). Thus, a linear decreasing trend of assisted people per month has been assumed in Figure 3d,e in the period from December 2018 up to December 2024 (see dot black line).

Figure 3 shows that, in the months immediately following the event, tents, hospitality in hotels and selfaccommodation grant, s.a.g., were widely used as assistance types. Then a significant portion of people started to be assisted in M.A.P. and C.A.S.E. Assistance in tents, hotels and s.a.g. fully ended after 8, 45, and 71 months, respectively (Figure 3a,b,c). After 108 months, 8,024 and 2,149 people were assisted in C.A.S.E and M.A.P. (Figure 3d,e).

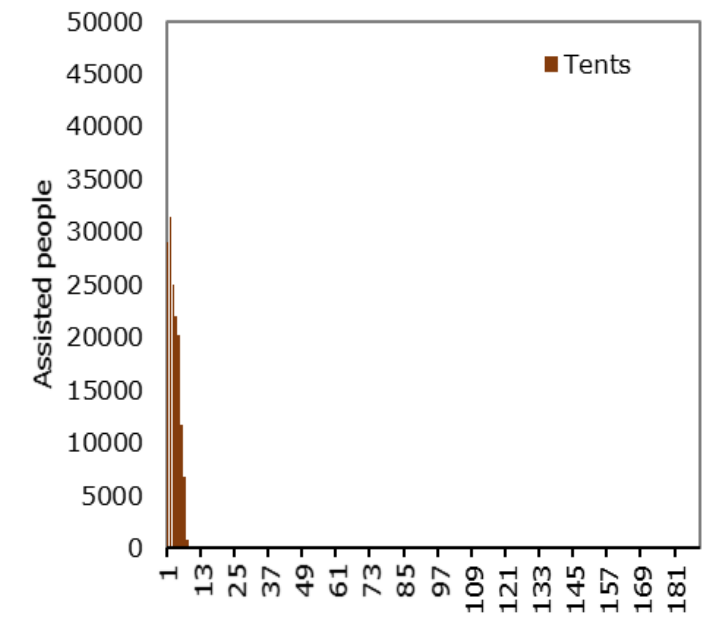

Months

(a)

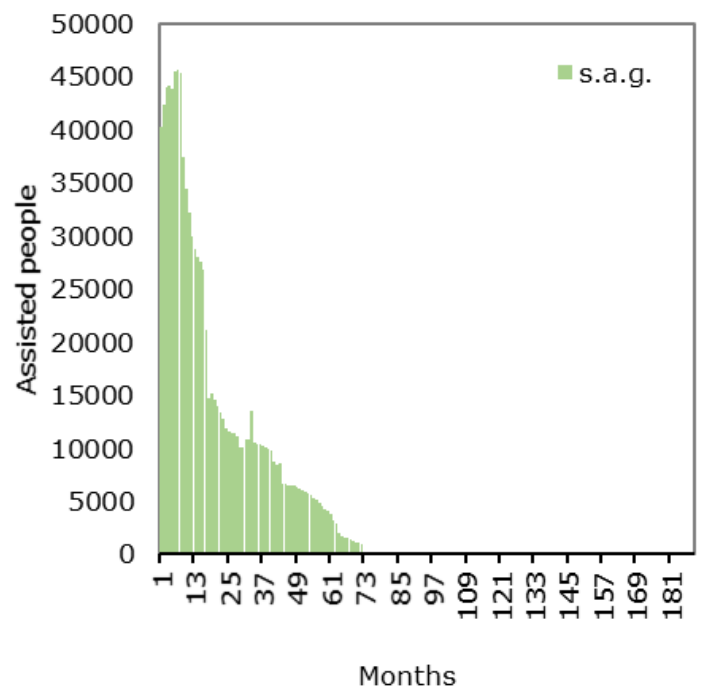

(c)

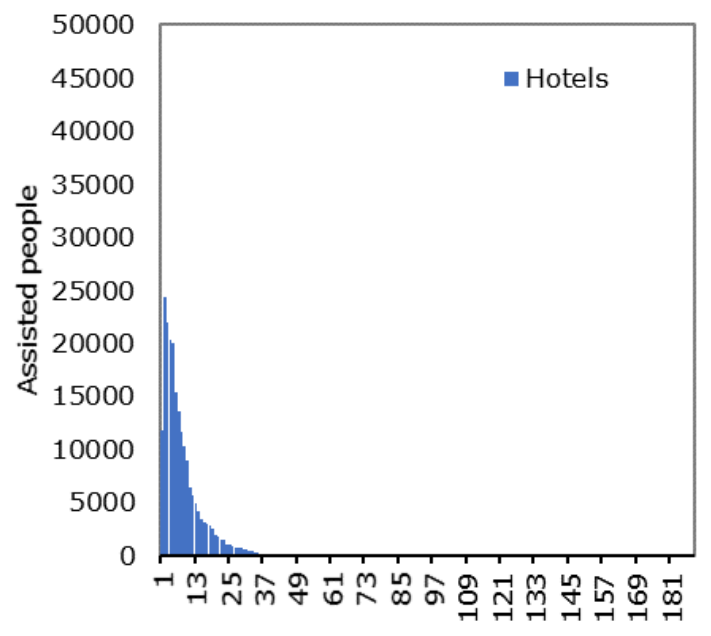

Months

(b)

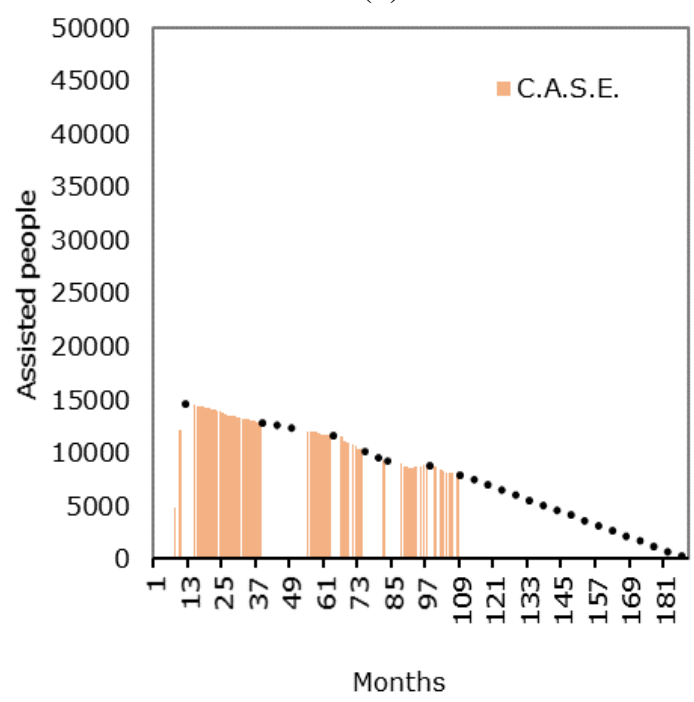

(d) 


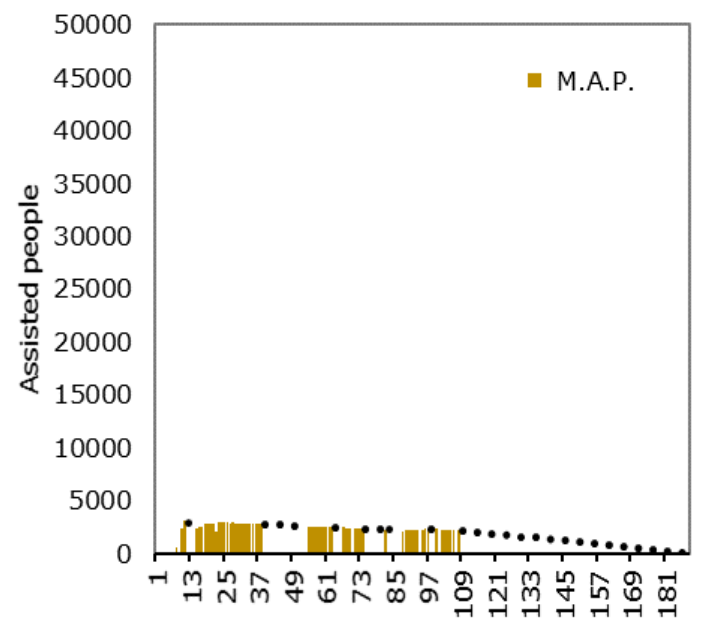

Months

(e)

Figure 3. Number of assisted people per month in tents (a), hotels (b), self-accommodation grant s.a.g. (c) C.A.S.E project (d) and M.A.P. (e).

The data related to number of assisted people per month allowed the costs associated to tents, hotels and s.a.g. to be directly calculated. The overall costs resulted to be about: 175 million euros for hospitality in tents (note that the cost of tent disposal is not taken into account while the costs include: supply of goods and services, extraordinary expenses for first assistance, supply of meals, foodstuffs, waste management, sanitation and cleaning, transport and temporary storage of furniture); 319 million Euros for hospitality in hotels; and 235 million Euros for the self-accommodation grant (s.a.g.). For these types of assistance, the costs are strictly correlated to the duration of the assistance and the public cost is sustained continuously over time. The ratio between the overall costs of the hospitality type and the sum of assisted people per month allowed to determine the average cost per month per person, $C_{i}$, for tents, hotels and s.a.g. accommodation types equal to: $€ 1191.20$; $€ 1524.40$; and $€ 227.40$ respectively. Table 7 summarizes for each assistance type the data related to the number of months of assistance and relevant mean number of people assisted per month in the period of assistance as well as the mean cost per month per person.

In case of C.A.S.E and M.A.P. assistance types, the initial costs for the construction of new facilities should be taken into account to define normalized costs per month per person. The construction of 1,113 M.A.P. amounted to about 116 million euros while that of C.A.S.E. project amounted to about 853 million euros for the construction of 185 buildings including 4449 apartments (http://www.protezionecivile.gov.it).

To define the assistance duration in M.A.P. and C.A.S.E assistance types, it has been assumed the end of the reconstruction in December 2024 (189 months); thus, according to graphs of Figure 3d,e it is possible to estimate a mean assistance cost per person per month of $€ 581.70$ and $€ 350.20$ for C.AS.E and MAP respectively. Note that such costs are not accounting for the residual economic value of the C.A.S.E. project buildings and for the possible revenue from potential alternative uses of the empty apartments before 2024 .

Table 6. Cost per person per month for different assistance types.

\begin{tabular}{|l|c|c|c|}
\hline $\begin{array}{l}\text { Assistance } \\
\text { form }\end{array}$ & $\begin{array}{l}\text { No. of months } \\
\text { of assistance }\end{array}$ & $\begin{array}{l}\text { Mean no. of people } \\
\text { assisted /month }\end{array}$ & $\begin{array}{c}\text { Mean Cost/month/ person, } \\
\boldsymbol{C}_{\boldsymbol{i}}\end{array}$ \\
\hline Tents & 8 & 18,335 & $€ 1,191.2$ \\
\hline Hotels & 45 & 4,650 & $€ 1,524.40$ \\
\hline s.a.g. & 72 & 14,325 & $€ 227.40$ \\
\hline C.A.S.E. project & 184 & 7,969 & $€ 581.70$ \\
\hline M.A.P. & 182 & 1,823 & $€ 350.20$ \\
\hline
\end{tabular}




\subsection{A METHODOLOGY TO NORMALIZE PEOPLE ASSISTANCE COSTS TO BUILDING RECOSNTRUCTION COST}

This section aims at defining a procedure to correlate the population assistance costs to each building as a function of its damage level expressed in terms of usability rating or damage state. In particular, the goal is to express the assistance costs in terms of percentage cost with respect to the reference unit cost of a new building, namely $\% C_{a}$ in the following.

To pursue such objective, a first step of the proposed procedure is the definition of a weighted population assistance cost per month, $C_{a, j}$, computed as:

$$
C_{a, j}=\sum_{i} \% \gamma_{i, j} \cdot C_{i}
$$

where $\% \gamma_{i, j}$ is the percentage of assisted people in the $i^{\text {th }}$ assistance type (tents, hotels, s.a.g., C.A.S.E. and M.A.P.) in the $j^{\text {th }}$ month; and $C_{i}$ is the mean cost per person per month in the $i^{\text {th }}$ assistance type. The distribution of $\% \gamma_{i, j}$ and the relevant $C_{a, j}$ expressed as $€ /$ month/person for each month in the period April 2009- December 2024 is depicted in Figure 4.

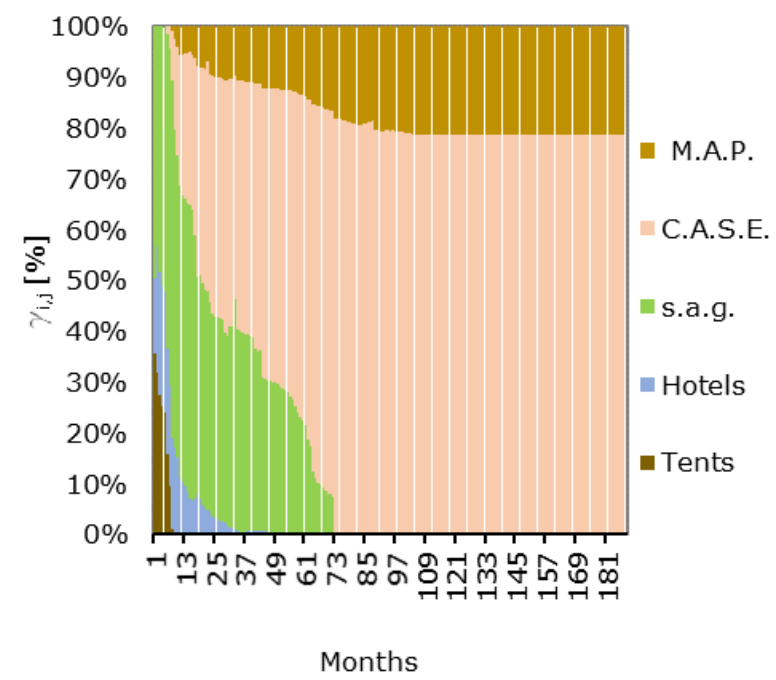

(a)

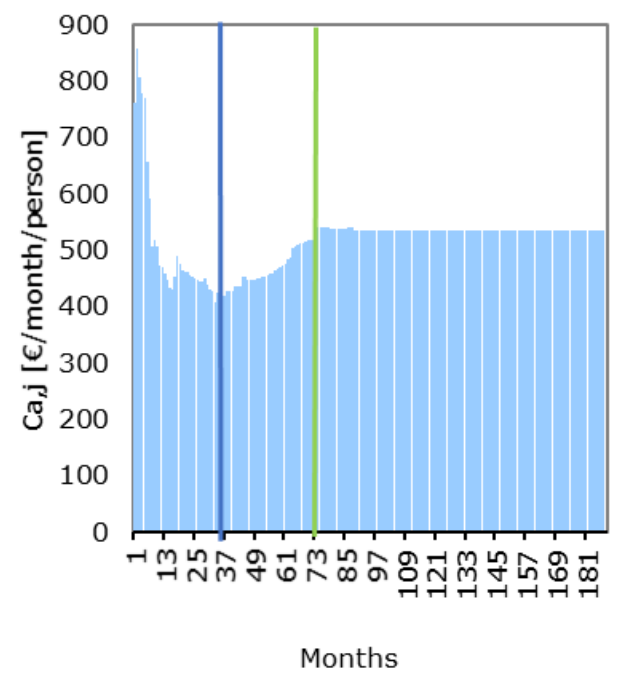

(b)

Figure 4. Distribution $\% \gamma_{i, j}(\mathrm{a})$ and $\mathrm{C}_{\mathrm{a}, \mathrm{j}}(\mathrm{b})$ in the reconstruction process period.

Once $C_{a, j}$ is computed, it is possible to compute $\% C_{a}$ for each building according to the following expression:

$\% C_{a}=\frac{\sum_{j=1}^{t} C_{a, j} \cdot n_{o c c}}{C U \cdot S_{L}}$

where $t$ is the period expressed in days of repair and strenghtening building site works; $n_{\text {occ }}$ is the number of building occupants derived from AeDES form; $C U$ is the reference unit cost of a new building assumed equal to $€ 1,350 / \mathrm{m}^{2}$; and $S_{L}$ is the overall building gross surface area. Note that expression (2) assumes that the people living in a building have been assisted according to the distribution $\% \gamma_{i, j}$ in the assistance period.

According to expressions (1) and (2), it was possible to assess the $\% C_{a}$ as a function of usability ratings, reconstruction classes or damage states of buildings; in particular, $\% C_{a}$ has been computed on a subset of 7,847 buildings out of 8,497 buidings due to the lack of information on number of occupants of 650 buildings.

\subsection{Usability rating}

The $\% C_{a}$ has been evaluated for 2,852 out of 3,502 unusable (i.e B-C and E rating buildings) buildings (see section §2) due to the lack of information on number of occupants on 650 buildings: $1,827 \mathrm{~B}-\mathrm{C}$ rating buildings (1,216 RC and 611 masonry buildings) and 1,025 E rating buildings (692 RC and 333 masonry buildings). The $\% C_{a}$ for usable buildings (i.e A rating buildings) is zero because no assistance is provided in this case. Figure 
5 shows the frequency distributions and the best fitting probability density function (PDF; log-normal) of $\% C_{a}$ for RC (Figure 5a,c) and masonry buildings (Figure 5b,d). The cumulative distribution function (CDF) of $\% C_{a}$ is also reported in each graph. Figure 5 shows that the log-normal function well approximates $\% C_{a}$ distributions.v

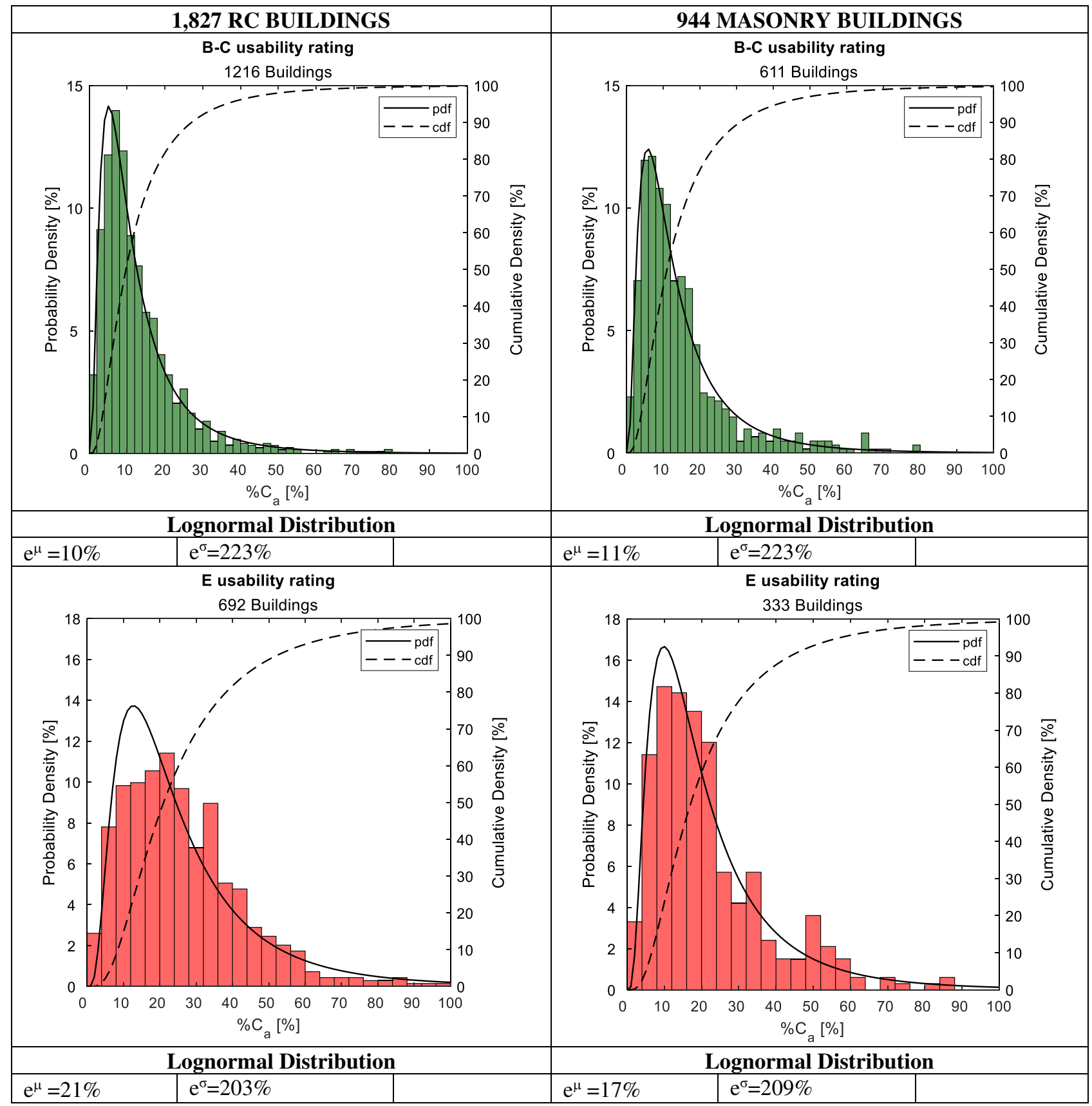

Figure 5. \% $C_{a}$ frequency distribution for RC $(\mathrm{a}, \mathrm{c})$ and masonry $(\mathrm{b}, \mathrm{d})$ buildings as a function of usability rating.

Table 7 summarizes the number of buildings and the median $16^{\text {th }}$ and $84^{\text {th }}$ percentile of $\% C_{a}$ computed for B$\mathrm{C}$ and $\mathrm{E}$ usability rating buildings. The data show that the impact of population assistance on the amount of costs sustained after the earthquake is really significant and it can also be comparable to that related to repair costs. In particular, mean [median] $\% C_{a}$ resulted on average comparable to mean [median] $\% C_{r}$ for lightly damaged buildings (i.e. B-C rating), see Table 4. This is because the population assistance of people living in lightly damaged buildings, even if it is not a long term assistance, mainly involves very expensive assistance types, that is the first emergency ones (i.e. tents and hotels). In case of severely damaged buildings mean [median] $\% C_{a}$ resulted on average less than half $\% C_{r}$ (see Table 4). This is because, according to the 
reconstruction process model used to calibrate such data, the long term assistance was provided by solutions characterized by significant initial costs but able to reduce normalized costs in a long period (i.e. C.A.S.E and M.A.P.). The coefficient of variation, $\mathrm{CoV}$, of $\% C_{a}$ resulted significantly higher in case of $\mathrm{E}$ rating buildings with respect to B-C ones, probably due to the significant uncertainties related to the duration of repair works and also to the influence of strengthening interventions aimed at achieving a threshold of $60 \%$ of the safety level required for new buildings (New Building Standards, \%NBS), Di Ludovico et al. 2017b. This can lead to significant differences in the execution of repair/strengthening works and thus on relevant assistance to population time. For the same reason, $\mathrm{CoV}$ for $\mathrm{E}$ rating buildings resulted greater for $\% C_{a}$ than for $\% C_{r}$.

Table 7. $\% C_{a}$, statistical parameters as a function of usability rating.

\begin{tabular}{|c|c|c|c|c|}
\hline & \multicolumn{2}{|c|}{ 1,908 RC buildings } & \multicolumn{2}{|c|}{944 Masonry buildings } \\
\hline Usability rating & B-C & $\bar{E}$ & B-C & $\bar{E}$ \\
\hline No. of buildings & 1216 & 692 & 611 & 333 \\
\hline$\% C_{a}-16^{\text {th }}$ percentile & $5 \%$ & $10 \%$ & $5 \%$ & $9 \%$ \\
\hline$\% C_{a}-$ median & $10 \%$ & $23 \%$ & $11 \%$ & $18 \%$ \\
\hline$\% C_{a}-84^{\text {th }}$ percentile & $21 \%$ & $41 \%$ & $24 \%$ & $35 \%$ \\
\hline$\% C_{a}$ mean & $13 \%$ & $26 \%$ & $15 \%$ & $22 \%$ \\
\hline$\% C_{a}$ standard deviation & $11 \%$ & $16 \%$ & $13 \%$ & $16 \%$ \\
\hline$\% C_{a}-\mathrm{CoV}$ & $119 \%$ & $161 \%$ & $115 \%$ & $139 \%$ \\
\hline
\end{tabular}

Figure 6 shows the frequency distributions and the best fitting probability density function (PDF; log-normal) of $\% C_{a}$ for RC (Figure $6 \mathrm{a}, \mathrm{c}, \mathrm{e}$ ) and masonry buildings (Figure $6 \mathrm{~b}, \mathrm{~d}, \mathrm{f}$ ) with reference to reconstruction classes related to $\mathrm{E}$ rating buildings (E-B, $\mathrm{E}_{\text {class }}$ and $\mathrm{E}_{\mathrm{dem}}$ ). The statistical parameters related to $\% C_{a}$ as a function of reconstruction classes are shown in Table 9. The analysis of data in terms of reconstruction class points out that the most significant mean [median] $\% C_{a}$ values refers to demolition and recostrucion class, that is up to $33 \%$ [30\%] and $28 \%$ [23\%] for RC and masonry buildings, respectively.

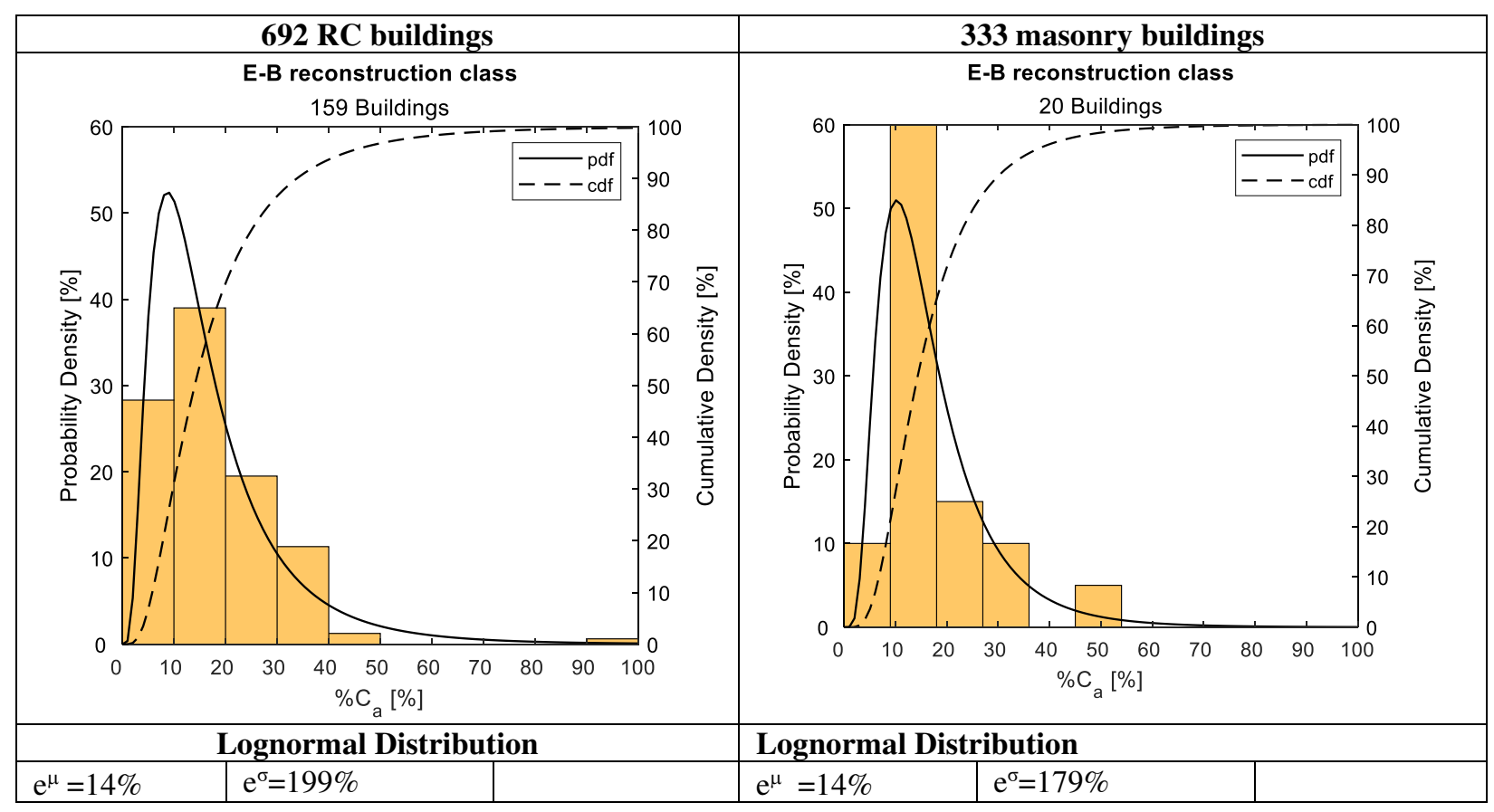




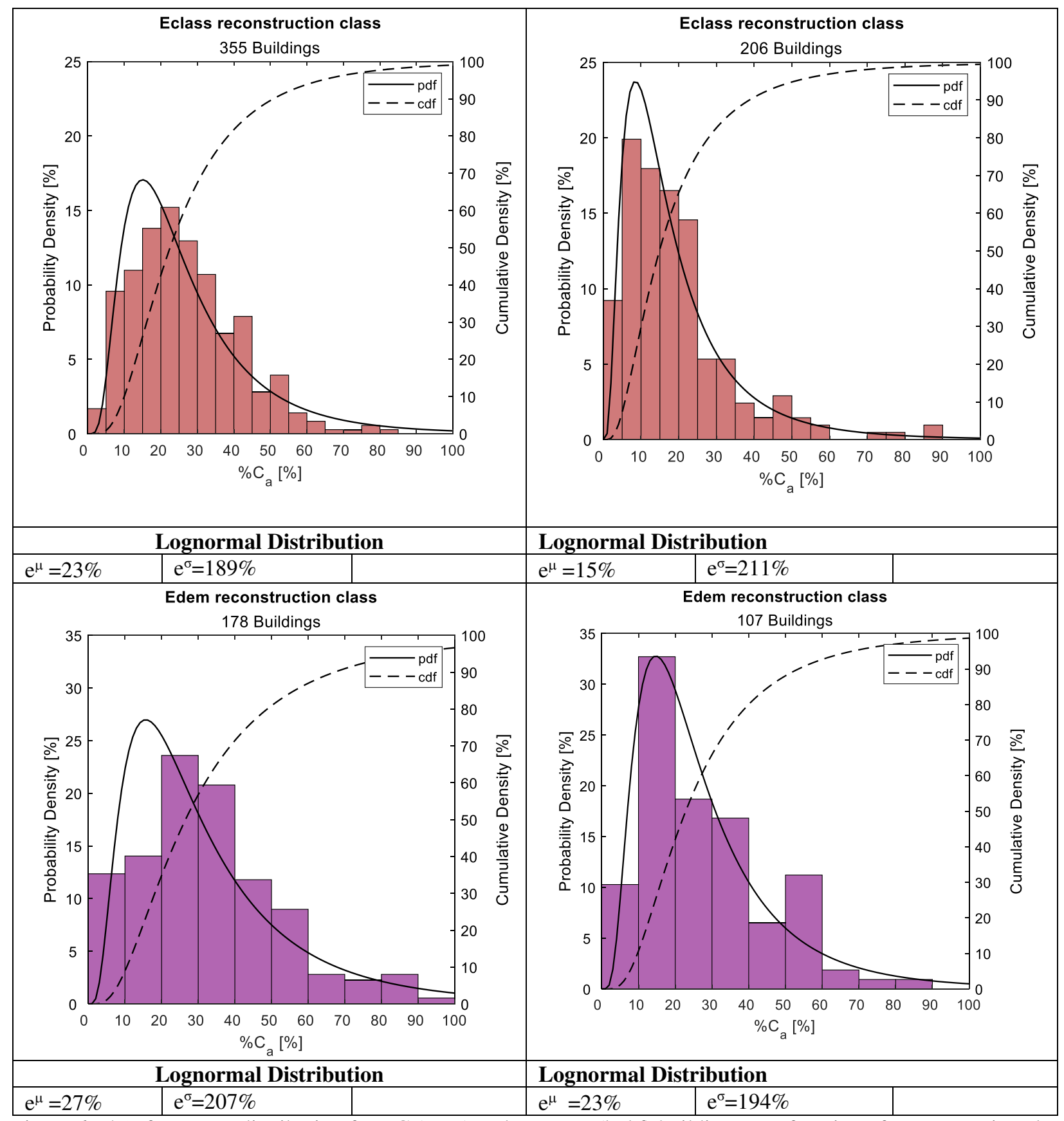

Figure 6. \% $C_{a}$ frequency distribution for RC $(\mathrm{a}, \mathrm{c}, \mathrm{e})$ and masonry $(\mathrm{b}, \mathrm{d}, \mathrm{f})$ buildings as a function of reconstruction class.

Table $8 . \% C_{a}$, statistical parameters as a function of reconstruction class.

\begin{tabular}{|c|c|c|c|c|c|c|}
\hline & \multicolumn{3}{|c|}{$692 \mathrm{RC}$ buildings } & \multicolumn{3}{|c|}{333 Masonry buildings } \\
\hline Reconstruction class & E-B & Eclass & Edem & E-B & Eclass & Edem \\
\hline No. of buildings & 159 & 355 & 178 & 20 & 206 & 107 \\
\hline$\% C_{a}-16^{\text {th }}$ percentile & $7 \%$ & $12 \%$ & $14 \%$ & $9 \%$ & $7 \%$ & $13 \%$ \\
\hline$\% C_{a}-$ median & $15 \%$ & $24 \%$ & $30 \%$ & $12 \%$ & $16 \%$ & $23 \%$ \\
\hline$\% C_{a}-84^{\text {th }}$ percentile & $27 \%$ & $41 \%$ & $51 \%$ & $27 \%$ & $30 \%$ & $49 \%$ \\
\hline$\% C_{a}$ mean & $17 \%$ & $27 \%$ & $33 \%$ & $17 \%$ & $19 \%$ & $28 \%$ \\
\hline$\% C_{a}$ standard deviation & $12 \%$ & $15 \%$ & $19 \%$ & $10 \%$ & $15 \%$ & $17 \%$ \\
\hline$\% \mathrm{Ca}-\mathrm{CoV}$ & $148 \%$ & $184 \%$ & $171 \%$ & $165 \%$ & $132 \%$ & $166 \%$ \\
\hline
\end{tabular}

In light of data derived and reported in Table 8 and Table 9 as well as Table 4 and Table 5, it is possible to estimate a mean cost due to repair plus assistance to population (i.e. $\% C_{r}+\% C_{a}$ ). For instance, it turns out to 
be about $27 \%$ and $31 \%$ for $\mathrm{B}-\mathrm{C}$ rating and about $77 \%$ and $74 \%$ for $\mathrm{E}$ rating $\mathrm{RC}$ and masonry buildings, respectively. This clearly indicate that reducing the number of severely damaged buildings not only reduces casualties but also cuts recovery costs per building of more than one third of its value.

\subsection{Damage state}

The $\% C_{a}$ has been evaluated for 7,847 buindings: 3,367 for DS0, 2,622 for DS1, 825 for DS2, 752 for DS3, 216 for DS4, and 65 for DS5.

Figure 7 shows the frequency distributions and the best fitting probability density function (PDF) of $\% C_{a}$ for RC (Figure 7a,c,e,g,i,m) and masonry buildings (Figure $7 \mathrm{~b}, \mathrm{~d}, \mathrm{f}, \mathrm{h}, \mathrm{l}, \mathrm{n}$ ) as a function of the buildings DS determined based on Del Gaudio et al 2019 and Dolce et al., 2019 conversion matrices. As for \% Cr, a mixture distribution (i.e. degenerate and lognormal) has been assumed to approximate the distribution of $\% \mathrm{C}_{\mathrm{a}}$ at DS1 and DS2. Note that for DS1, the probability to attain $\% C_{a}=0$ is $67 \%$ and $68 \%$ for RC and masonry buildings, respectively; it drastically drops down at DS2 (i.e. $8 \%$ both for RC and masonry buildings). Lognormal distributions has been assumed for DS3 and DS4 while a normal distribution and a lognormal one approximates well the distribution of $\% \mathrm{C}_{\mathrm{r}}$ at DS5.

The number of buildings belonging to each DS as well as the cumulative distribution function (CDF) of $\% C_{a}$ are also reported in each graph. The statistical parameters related to $\% C_{a}$ as a function of DSs are shown in Table 9 . The data clearly show an increasing trend of $\% C_{a}$ with respect to DS, but less significant of that found for $\% C_{r}$, see Table 9 . The CoV also increase by increasing DSs indicating the significant variability of population assistance time in case of severe damage.

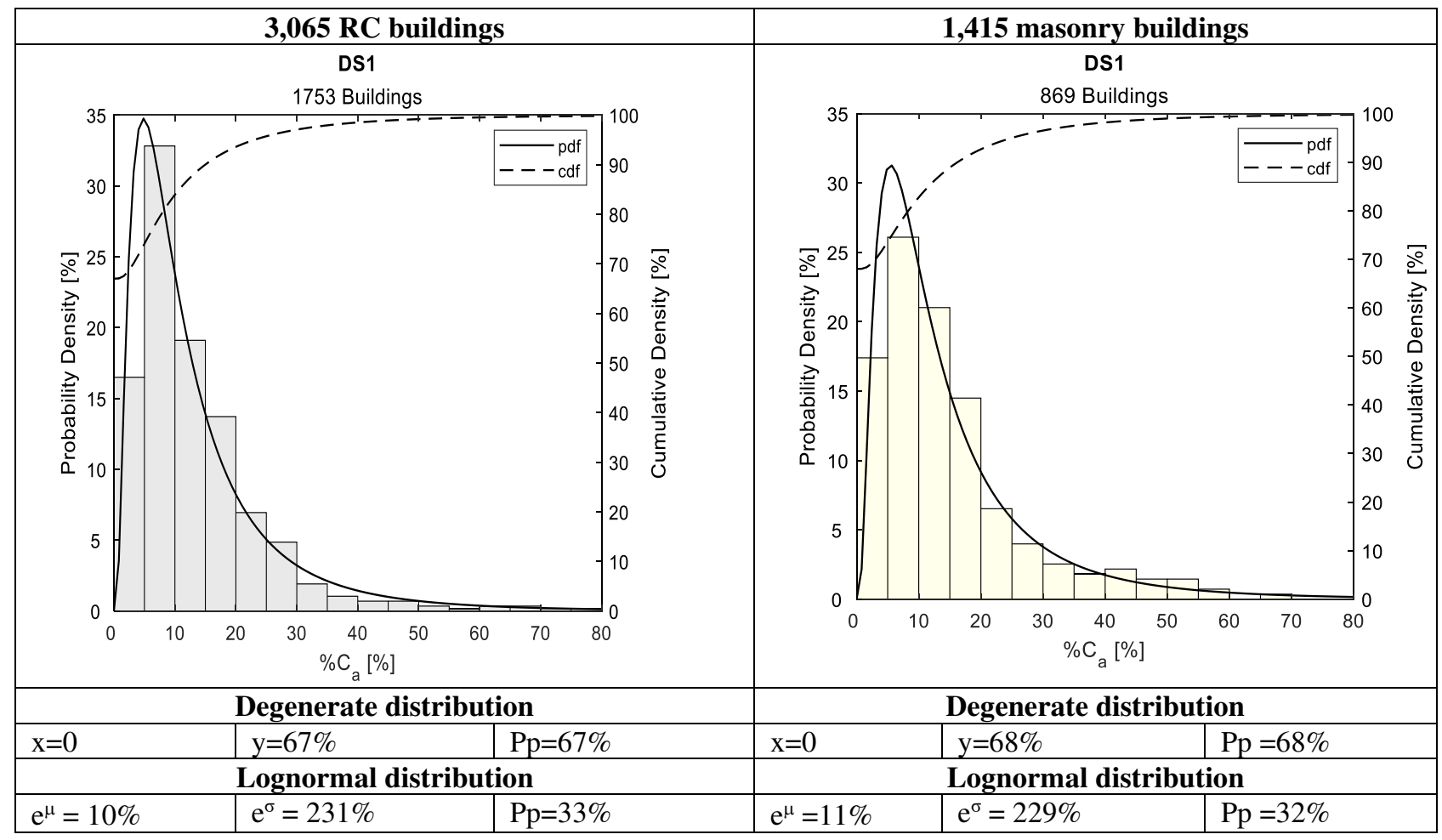




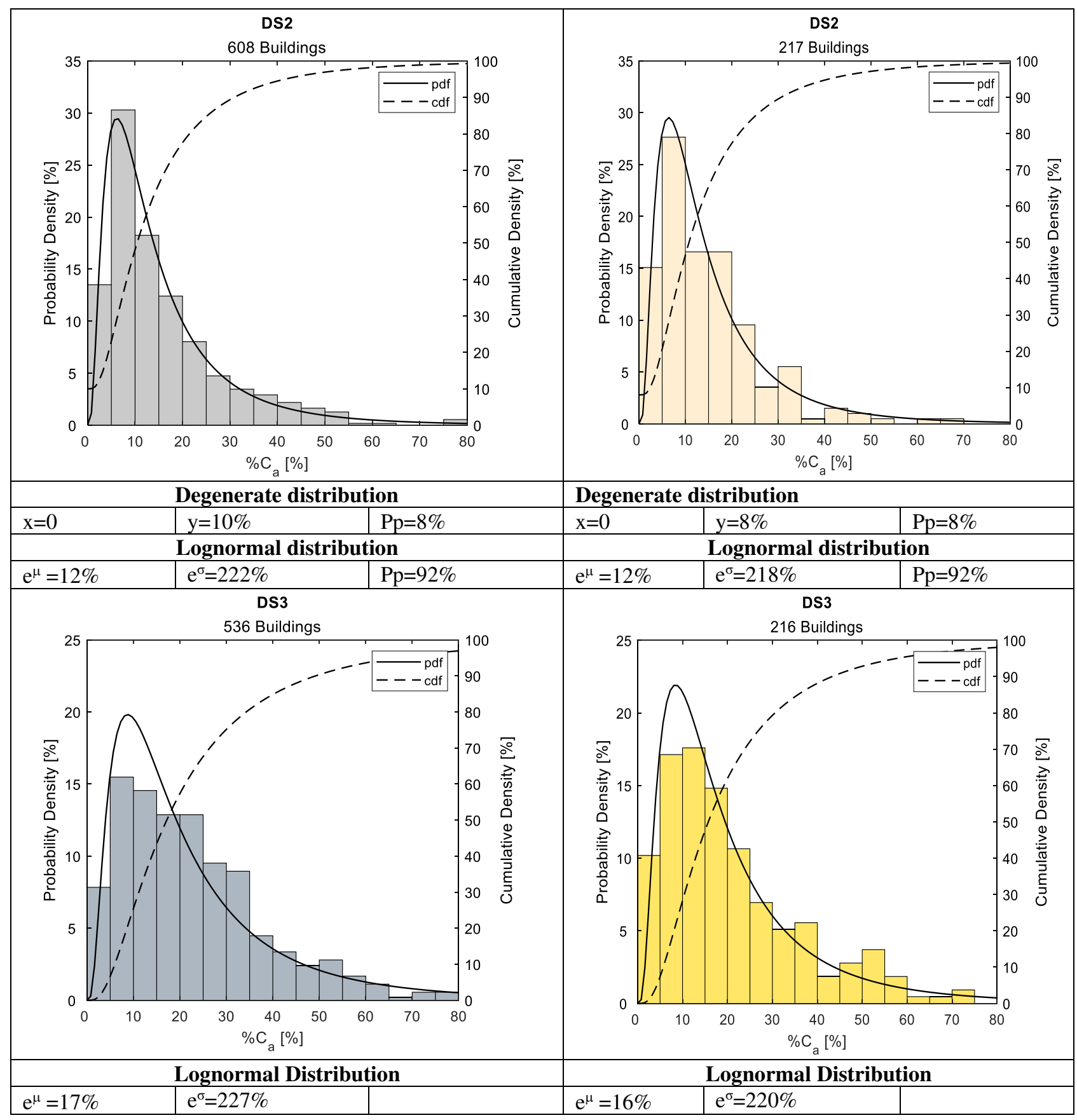




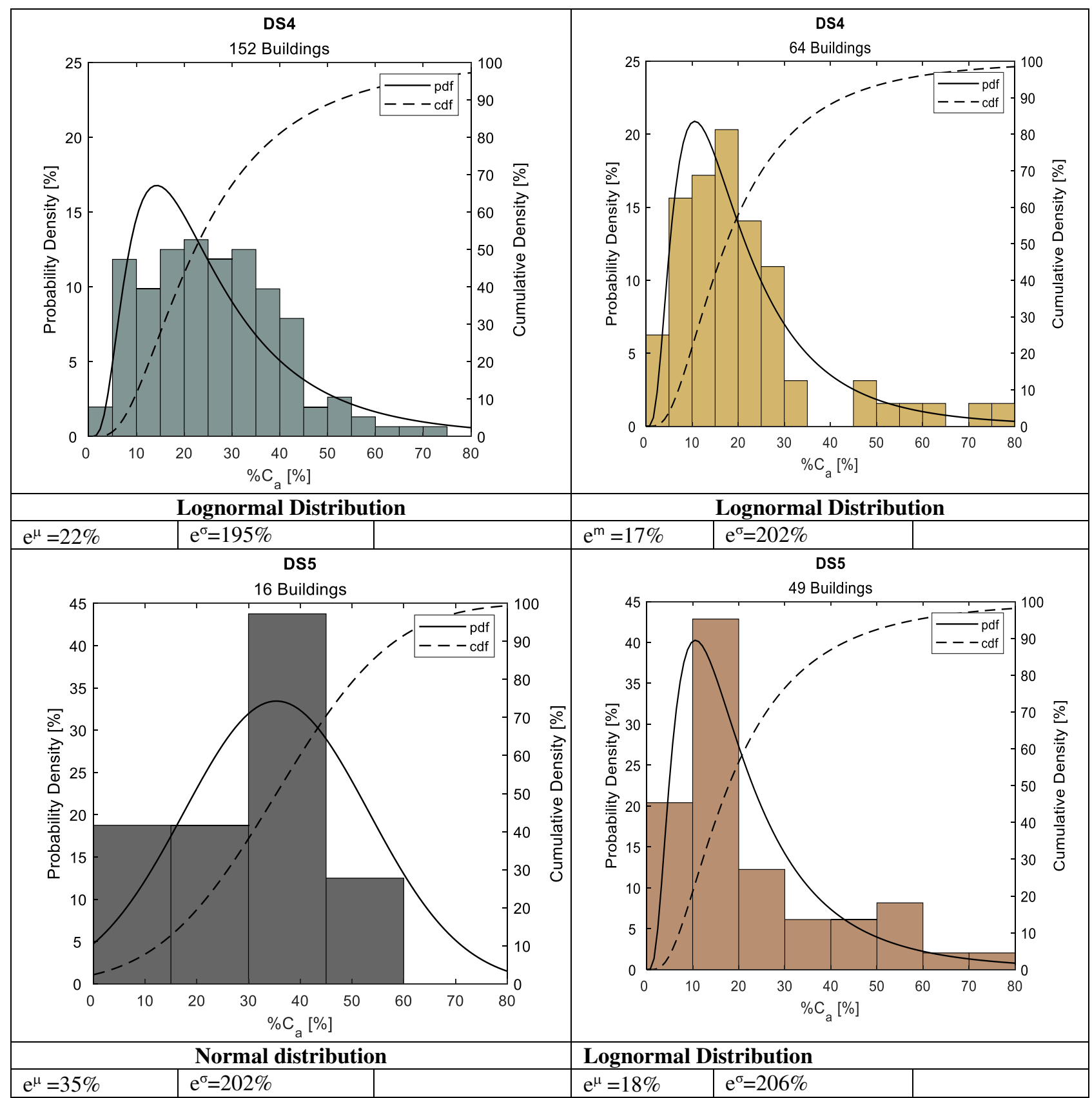

Figure 7. Frequency distribution of $\% C_{a}$ related to $\mathrm{RC}(\mathrm{a}, \mathrm{c}, \mathrm{e}, \mathrm{g}, \mathrm{i}, \mathrm{m})$ and masonry $(\mathrm{b}, \mathrm{d}, \mathrm{f}, \mathrm{h}, \mathrm{l}, \mathrm{n})$ buildings at different damage state.

Table 9. Percentage assistance costs with respect to reference unit costs, $\% C_{a}$, as a function of damage states, $D S$.

\begin{tabular}{|c|c|c|c|c|c|c|c|c|c|c|}
\hline \multirow[b]{2}{*}{ Reconstruction class } & \multicolumn{5}{|c|}{ 4,329 $\mathrm{RC}$ buildings } & \multicolumn{5}{|c|}{ 3,518 masonry buildings } \\
\hline & DS1 & DS2 & DS3 & DS4 & DS5 & DS1 & DS2 & DS3 & DS4 & DS5 \\
\hline No. of buildings & 1,753 & 608 & 536 & 152 & 16 & 869 & 217 & 216 & 64 & 49 \\
\hline$\% C a$ - 16th percentile & $0 \%$ & $3 \%$ & $8 \%$ & $11 \%$ & $15 \%$ & $0 \%$ & $4 \%$ & $7 \%$ & $8 \%$ & $9 \%$ \\
\hline$\% C a$ - median & $0 \%$ & $10 \%$ & $20 \%$ & $25 \%$ & $38 \%$ & $0 \%$ & $11 \%$ & $16 \%$ & $19 \%$ & $18 \%$ \\
\hline$\% C a-84$ th percentile & $10 \%$ & $25 \%$ & $37 \%$ & $40 \%$ & $47 \%$ & $11 \%$ & $24 \%$ & $36 \%$ & $29 \%$ & $46 \%$ \\
\hline$\% C a$ mean & $4 \%$ & $14 \%$ & $23 \%$ & $27 \%$ & $35 \%$ & $5 \%$ & $14 \%$ & $21 \%$ & $22 \%$ & $23 \%$ \\
\hline \%Ca standard deviation & $9 \%$ & $14 \%$ & $16 \%$ & $15 \%$ & $17 \%$ & $10 \%$ & $13 \%$ & $15 \%$ & $17 \%$ & $17 \%$ \\
\hline$\% \mathrm{Ca}-\mathrm{CoV}$ & $206 \%$ & $95 \%$ & $71 \%$ & $55 \%$ & $51 \%$ & $206 \%$ & $93 \%$ & $74 \%$ & $78 \%$ & $75 \%$ \\
\hline
\end{tabular}




\section{EMPIRICAL RELATIONSHIP BETWEEN REPAIR AND POPULATION ASSISTANCE COSTS}

The probability density functions of $\% C_{r}$ and $\% C_{a}$ can be used for the assessment of seismic loss scenarios at large scale because allow to associate repair and population assistance costs to different usability rating or damage levels, obtained by using post-earthquake data or empirical/mechanical based fragility curves. Recently, significant research efforts have been dedicated to developing loss-assessment methodologies to predict earthquake losses at the building level (Welch et al. 2012) and some refined ones focus on predictions of earthquake losses at the component level (FEMA P-58, ATC 58, 2012a, implemented in user-friendly software ATC 58, 2012b; Haselton and Baker, 2018; Del Gaudio et al. 2018; Del Vecchio et al. 2020). In order to provide a tool to rapidly associate at building level the direct costs expressed as repair costs to the indirect costs expressed as the portion due to population assistance costs, an empirical based relationship is presented in this section. In particular, according to data and methodologies presented (and relevant assumptions), it has been possible to associate repair costs to population assistance costs for each building of the database herein discussed, that is 7,912 buildings. The $\% C_{r}-\% C_{a}$ points for RC and masonry buildings are depicted in Figure 8 along with the best fitting of data; because the trend of points related to RC and masonry buildings are quite similar a single relationship has been herein derived.

The best fitting function has been calibrated on points with $\% C_{r}$ greater than $5 \%$ that corresponds to maximum (between RC and masonry buildings) $84^{\text {th }}$ percentile $\% C_{r}$ on A rating buildings, see Table 4 . This accounts for the no need of assistance in case of A rating buildings. Figure 8 show that a bi-linear trend can be assumed for $\% C_{r}>5 \%$; in particular the first linear branch (i.e. in the range $\% C_{r}=5 \%$ up to $\% C_{r}=25 \%$, that is the maximum between $\mathrm{RC}$ and masonry buildings $84^{\text {th }}$ percentile $\% C_{r}$ on $\mathrm{B}-\mathrm{C}$ rating buildings) has a greater inclination than the second linear branch. The best fitting bi-linear function has $\mathrm{R}^{2}=0.28$.

Thus, a very simple tri-linear $\% C_{r}-\% C_{a}$ relationship (a first constant branch followed by two linear ones) has been determined and can be expressed as follows, see Figure 8b:

$$
\begin{cases}\% C_{a}=0 & \text { for } \% \mathrm{C}_{\mathrm{r}} \leq 5 \% \\ \% C_{a}=0.77 C_{r} & \text { for } 5 \%<\% \mathrm{C}_{\mathrm{r}} \leq 25 \% \\ \% C_{a}=0.19 C_{r}+0.15 & \text { for } \% \mathrm{C}_{\mathrm{r}}>25 \%\end{cases}
$$

Altough a significat dispersion of data can be observed, the relationship (4) can be used to directly estimate $\% C_{a}$ by only known $\% C_{r}$ derived by using literature available procedures.

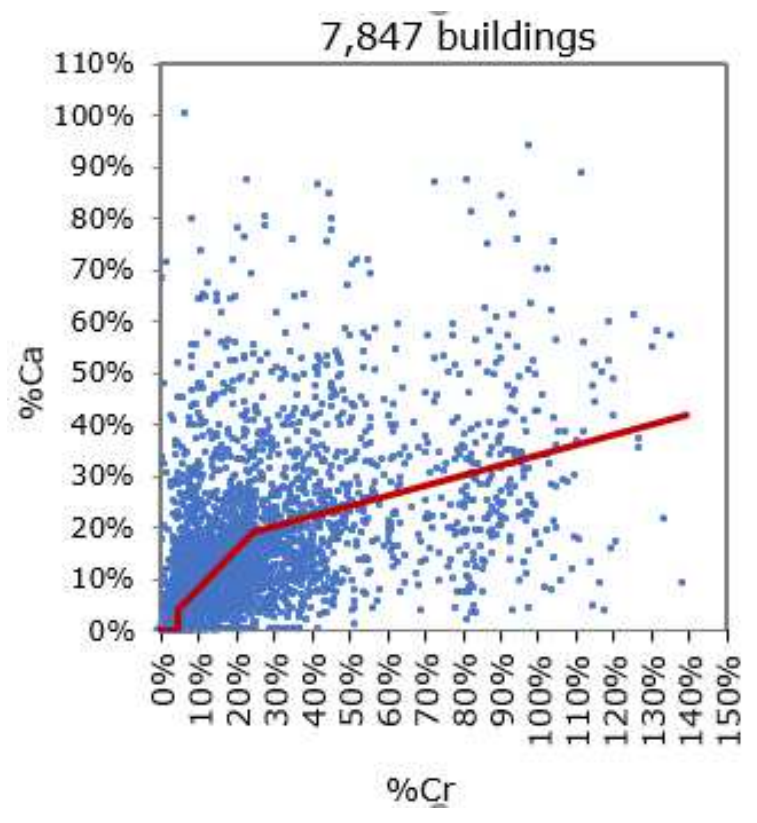

Figure $8 . \% \mathrm{Cr}-\% \mathrm{Ca}$ relationships: tri linear trend. 


\section{CONCLUSIONS}

This paper illustrates the relationships between empirical damage and direct/indirect losses on residential reinforced concrete and masonry buildings. The relationships have been derived from a database of 8,497 buidings damaged by L'Aquila 2009 earthquake. In particular, probability density functions and relevant statistics have been determined to correlate repair costs and population assistance costs (expressed in terms of percentage of cost with respect to the reference unit cost of a new building, $\% C_{r}$ and $\% C_{a}$ ) as a function of buildings damage. The damage is expressed in several ways: usability rating (A, B-C or E usability rating for undamaged, lightly or severely damaged buildings); reconstruction classes (class E-B, including buildings with a high non-structural damage but with slight structural damage; $\mathrm{E}_{\text {class }}$ including buildings with severe structural damage, and $\mathrm{E}_{\mathrm{dem}}$, including buildings that needed to be demolished); global damage states according to European Macroseismic Scale (EMS-98), DS, from DS1 to DS5 determined on the basis of literature available rules to convert empirical damage to structural and non-structural components into building global damage. The $\% C_{r}$ frequency distributions were derived from repair intervention costs computed by practitioners engaged by property owners to apply for public grant for reconstruction, while $\% C_{a}$ were obtained by using a methodology developed to associate population assistance time and costs to single buildings. The relationships between costs and usability performances of buildings are particularly suitable in the immediate postearthquake to rapidly estimate reconstruction costs, while those between costs and damage states represent a crucial tool to define territorial scale loss scenario by using empirical or mechanically based fragility curves. Furthermore, an empirical based relationship has been calibrated to directly correlate repair costs on a building with assistance costs to their occupants which could be an essential tool to fully exploit the potential of available literature methods to provide refined estimation of repair costs at building level.

The main findings of this study are:

- mean [median] $\% C_{r}$ resulted 2\% [0\%], 14\% [12\%], 51\% [43\%] for A (usable), B-C (unusable with light structural damage), E rating (unusable with severe structural damage) RC buildings and $2 \%$ [0\%], $16 \%$ [14\%], 52\% [42\%]for A, B-C, E rating masonry ones; the coefficient of variations, CoV, of E rating buildings were generally lower than that related to B-C rating ones due the high variability of costs related to actions aimed at restoring non-structural components;

- a significant portion of $\mathrm{E}$ rating buildings, about one-third, were demolished, $\mathrm{E}_{\mathrm{dem}}$ reconstruction class, because economically convenient due to $\% C_{r}$ close to $100 \%$;

- according to matrices adopted to convert empirical damage on components to a global building damage state, DS, resulted that: A rating buildings mostly belongs to DS0 or DS1; B-C rating to DS1 or DS2; E rating to DS3; damage states DS4 and DS5 attains their peak values in the case of $\mathrm{E}_{\mathrm{dem}}$ reconstruction class;

- the best fitting probability density functions of $\% C_{r}$ as a function of DS for RC and masonry buildings resulted a mixture of a degenerate (discrete) and lognormal (continuous) distribution for DS1-DS2, a mixture of two lognormal distributions for DS3-DS4, and a normal (RC buildings) or a mixture of normal and lognormal distributions (masonry buildings) for DS5; mean [median] $\% C_{r}$ from DS1 to DS5 resulted 6\% [3\%], 19\% [14\%], 39\% [34\%], 62\% [59\%], 78\% [81\%] for RC buildings and 8\% [4\%], 22\% [17\%], 41\% [33\%], 59\% [52\%], 67\% [72\%] for masonry buildings;

- the average cost per month per person, $C_{i}$, to assist people in different accommodation types resulted: $€ 1191,20$ for tents; $€ 1524,40$ for hotels; and $€ 227,40$ for s.a.g. (self-accommodation grant); $€ 581.70$ for C.A.S.E. (Anti-seismic, Sustainable and Ecologically Compatible Housing Complexes) project; and $€ 350.20$ for M.A.P. (Temporary Inhabitable Modules);

- mean [median] $\% C_{a}$ resulted on average comparable to mean [median] $\% C_{r}$ for lightly damaged buildings (i.e. B-C rating) while on average resulted less than half $\% \mathrm{Cr}$ in case of severely damaged buildings (i.e. E rating);

- the best fitting probability density functions of $\% C_{a}$ as a function of DS resulted a mixture of a degenerate and lognormal distribution for DS1-DS2, lognormal distributions for DS3-DS4, and a normal (RC buildings) or lognormal distribution (masonry buildings) for DS5; mean [median] $\% C_{a}$ from DS1 to DS5 resulted 4\% [0\%], 14\% [10\%], 23\% [20\%], 27\% [25\%], 35\% [38\%] for RC buildings and $5 \%$ [0\%], 14\% [11\%], 21\% [16\%], 22\% [19\%], 23\% [17\%] for masonry buildings: 
- $\mathrm{CoV}$ of $\% C_{a}$ increases by increasing DSs indicating the significant variability of population assistance time in case of severe damage;

- a simple empirical based relationship to associate repair costs to population assistance costs for each building can be expressed by using a tri-linear relationship: $\% C_{a}=0$ for $\% C r<5 \% ; \% C_{a}=0.77 \% \mathrm{Cr}$ for $5 \% \leq \% C r \leq 25 \%$; and $\% C_{a}=0.19 \% C r+0.15$ for $\% C r>25 \%$.

The above results are drawn form data relevant to a single event, which also means a specific model of assistance to the population (tents, MAP, CASE, s.a.g.). Different models adopted for different events and in different socio-economic conditions can obviously lead to different results. Further data are therefore needed to provide more reliable and robust relationships or even relationships relevant to different models of population assistance. However, the unique and comprehensive data presented provided the opportunity to derive useful relationships o derive loss scenarios and drive decisions makers involved in the definition and planning of suitable seismic risk mitigation policies.

\section{AKNOWLEDGMENTS}

This study was performed within the framework of the PE2019-2021 joint program DPC-ReLUIS, WP4: "Seismic Risk Maps-MARS", Task 4.4. "Risk: evaluation of consequences and economic losses".

\section{REFERENCES}

1. RISK-UE (2001-2004) An advanced approach to earthquake risk scenarios, with applications to different European cities. http://www.risk-ue.net.

2. Zuccaro G (2004) Inventory and vulnerability of the residential building stock at a national level, seismic risk and social/economic loss maps. CD-ROM, Naples, Italy.

3. Lagomarsino G. and Giovinazzi S., 2006. Macroseismic and mechanical models for the vulnerability and damage assessment of current buildings. Bulletin of Earthquake Engineering, 4, 415-443.

4. K. Pitilakis, M. Alexoudi, S. Argyroudis, A. Anastasiadis Seismic risk scenarios for an efficient seismic risk management: the case of Thessaloniki (Greece) Advances in Earthquake Engineering for Urban Risk Reduction, Springer, Dordrecht (2006), pp. 229-244.

5. H. Shakib, S.D. Joghan, M. Pirizadeh Proposed seismic risk reduction program for the megacity of Tehran, Iran Nat. Hazards Rev., 12 (3) (2011), pp. 140-145.

6. V. Silva, H. Crowley, H. Varum, R. Pinho Seismic risk assessment for mainland Portugal Bull. Earthq. Eng., 13 (2) (2015), pp. 429-457.

7. H. Chaulagain, H. Rodrigues, V. Silva, E. Spacone, H. Varum Seismic risk assessment and hazard mapping in Nepal Nat. Hazards, 78 (1) (2015), pp. 583-602.

8. National Department of Civil Protection (NDCP, ed., 2018) National risk assessment: overview of the potential major disasters in Italy http://www.prote zione civil e.gov.it/docum ents/20182 /82380 $\underline{3 / \text { Documento+sulla }+ \text { Valut azion e+nazio nale+dei+risch i/57f33 7fd-a421-4cb0-b04c-234b6 }}$ 1997a 2f.

9. Silva V., Pagani M., Schneider J., Henshaw P., 2019. Assessing Seismic Hazard and Risk Globally for an Earthquake Resilient World. Global Earthquake Model Foundation (GEM), https://www.globalquakemodel.org/.

10. M. Dolce, A. Prota, B. Borzi, F. da Porto, S. Lagomarsino, G. Magenes, C. Moroni, A. Penna, M. Polese, E. Speranza, G. M. Verderame, G. Zuccaro (2020). Seismic risk assessment of residential buildings in Italy. Bulletin of Earthquake Engineering, S.I. : Seismic Risk Assessment in Italy. https://doi.org/10.1007/s10518-020-01009-5.

11. Spence RJS, Coburn AW, Pomonis A (1992) Correlation of ground motion with building damage: the definition of a new damage-based seismic intensity scale. In: Proceedings of 10th world conference on earthquake engineering, Balkema, Rotterdam.

12. M.W. Musson Intensity-based seismic risk assessment Soil Dyn. Earthq. Eng., 20 (2000), pp. 353-360

13. Rossetto T, Ioannou I, Grant DN, Maqsood T (2014) Guidelines for empirical vulnerability assessment. GEM Technical Report 2014-X, GEM Foundation, Pavia. 
14. F Braga, M Dolce, D Liberatore (1982). A statistical study on damaged buildings and an ensuing review of the MSK-76 scale. Proceedings of the seventh European conference on earthquake engineering, Athens, Greece, p. 431-450

15. T. Rossetto, A. Elnashai Derivation of vulnerability functions for European-type RC structures based on observational data Eng. Struct., 25 (2003), pp. 1241-1263

16. Rota M, Penna A, Strobbia CL (2008) Processing Italian damage data to derive typological fragility curves. Soil Dyn Earthq Eng 28(10):933-947

17. G. Zuccaro, F. Cacace Seismic vulnerability assessment based on typological characteristics. The first level procedure "SAVE” Soil Dyn. Earthq. Eng., 69 (2015), pp. 262-269

18. C. Del Gaudio, G. De Martino, M. Di Ludovico, G. Manfredi, A. Prota, P. Ricci, G.M. Verderame Empirical fragility curves from damage data on RC buildings after the 2009 L'Aquila earthquake Bull. Earthq. Eng., 15 (4) (2017), pp. 1425-1450

19. Rosti A, Rota M, Penna A (2018) Damage classification and derivation of damage probability matrices from L'Aquila (2009) post-earthquake survey data. Bull Earthq Eng 16(9):3687-3720

20. Del Gaudio C, De Martino G, Di Ludovico M, Manfredi G, Prota A, Ricci P, Verderame GM (2019) Empirical fragility curves for masonry buildings after the 2009 L'Aquila, Italy, earthquake. Bull Earthq Eng 17(11):6301-6330.

21. Del Gaudio C, Di Ludovico M, Polese M, Manfredi G, Prota A, Ricci P, Verderame GM (2020 Seismic fragility for Italian RC buildings based on damage data of the last 50 years). Bull Earthq Eng 18, $2023-$ 2059.

22. Rosti, A., Del Gaudio, C., Rota, M, Ricci P., Di Ludovico M., Penna A., Verderame G.M. Empirical fragility curves for Italian residential RC buildings. Bull Earthquake Eng (2020). https://doi.org/10.1007/s10518-020-00971-4

23. T. Rossetto, A. Elnashai A new analytical procedure for the derivation of displacement-based vulnerability curves for populations of RC structures Eng. Struct., 27 (3) (2005), pp. 397-409.

24. B. Borzi, R. Pinho, H. Crowley Simplified pushover-based vulnerability analysis for large scale assessment of RC buildings Eng. Struct., 30 (3) (2008), pp. 804-820.

25. M. Rota, A. Penna, G. Magenes A methodology for deriving analytical fragility curves for masonry buildings based on stochastic nonlinear analyses 2010 Eng. Struct., 32 (5) (2010), pp. 1312-1323

26. Guha-Saphir D \& Santos I. (Eds.) The Economic Impacts of Natural Disasters. OUP, USA, 368 pages (2013).

27. Mannella A., Di Ludovico M., Sabino A., Prota A., Dolce M., Manfredi G., 2017. Analysis of the population assistance and returning home in the reconstruction process of the 2009 L'Aquila earthquake, Sustainability, 9 (8), 1395.

28. Benson, Charlotte; Clay, Edward J., 2004. Understanding the Economic and Financial Impacts of Natural Disasters. Disaster Risk Management series; 4. Washington, DC: World Bank. () World Bank. https://openknowledge.worldbank.org/handle/10986/15025 License: CC BY 3.0 IGO."

29. Di Ludovico, M., Prota A., Moroni C., Manfredi G., and Dolce M., 2017a. Reconstruction process of damaged residential buildings outside the historical centres after L'Aquila earthquake - part I: "light damage" reconstruction. Bulletin of Earthquake Engineering 15, 667-692.

30. Di Ludovico, M., Prota A., Moroni C., Manfredi G., and Dolce M., 2017b. Reconstruction process of damaged residential buildings outside the historical centres after L'Aquila earthquake - part II:"heavy damage" reconstruction. Bulletin of Earthquake Engineering 15, 693-729.

31. Baggio C, Bernardini A, Colozza R, Coppari S, Corazza L, Della Bella M, Di Pasquale G, Dolce M, Goretti A, Martinelli A, Orsini G, Papa F, Zuccaro G (2007) Field manual for post-earthquake damage and safety assessment and short term countermeasures. In: Pinto A, Taucer F (eds) Translation from Italian: Goretti A, Rota M, JRC Scientifc and Technical Reports, EUR 22868 EN-2007.

32. Goretti A. and Inukai M.; 2002: Post-earthquake usability and damage evaluation of reinforced concrete buildings designed not according to modern seismic codes. JSPS Short Term Fellowship, Final report, Servizio Sismico Nazionale, Dipartimento di Protezione Civile, Roma, Italy.

33. ATC (Applied Technology Council); 2005: ATC-20-1. Field manual: postearthquake safety evaluation of buildings, second edition. Applied Technology Council, Redwood City, CA, USA.

34. NZSEE (New Zealand Society for Earthquake Engineering); 2009: Building safety evaluation during a state of emergency guidelines for Territorial Authorities. 
http://www.dbh.govt.nz/UserFiles/File/Building/information\%20for/Building-Safety-Evaluation-duringState-of-Emergency.pdf.

35. De Martino, G., Di Ludovico M., Prota A., Moroni C., Manfredi G., Dolce M., 2017. Estimation of repair costs for RC and masonry by post-earthquake visual inspection. Bulletin of Earthquake Engineering, 15, 1681-1706.

36. Del Vecchio, C., M. Di Ludovico, S. Pampanin, and A. Prota. 2018. Repair costs of existing RC buildings damaged by the L' Aquila earthquake and comparison with FEMA P-58 predictions. Earthquake Spectra 34: 237-263. doi:https://doi.org/10.1193/122916EQS257M.

37. Del Vecchio, C., M. Di Ludovico, S. Pampanin, and A. Prota. 2020. Repair costs of reinforced concrete building components: From actual data analysis to calibrated consequence functions. Earthquake Spectra 2020, 36(1), pp. 353-377.

38. Cosenza, E., C. Del Vecchio, M. Di Ludovico, M. Dolce, C. Moroni, A. Prota, and E. Renzi. 2018. The Italian guidelines for seismic risk classification of constructions: technical principles and validation. Bulletin of Earthquake Engineering. Vol. 16. Springer Netherlands. doi:10.1007/s10518-018-0431-8.

39. Ordinance of the President of the Council of Ministers. O.P.C.M. n. 3778 (2009) Urgent interventions to deal with seismic events occurred in the Abruzzo region on April 6. 2009 and other urgent civil protection provisions. (In Italian). O.P.C.M. n. 3779 del 6 giugno 2009 - "Ulteriori interventi urgenti diretti a fronteggiare gli eventi sismici verificatisi nella regione Abruzzo il giorno 6 aprile 2009 e altre disposizioni urgenti di protezione civile'. Pubblicata nella Gazzetta Ufficiale n. 132 del 10 giugno 2009'’.

40. Ordinance of the President of the Council of Ministers. O.P.C.M. n. 3779 (2009) Urgent interventions to deal with seismic events occurred in the Abruzzo region on April 6. 2009 and other urgent civil protection provisions. (In Italian). O.P.C.M. n. 3779 del 6 giugno 2009 - "Ulteriori interventi urgenti diretti a fronteggiare gli eventi sismici verificatisi nella regione Abruzzo il giorno 6 aprile 2009 e altre disposizioni urgenti di protezione civile'”. Pubblicata nella Gazzetta Ufficiale n. 132 del 10 giugno 2009'”.

41. Ordinance of the President of the Council of Ministers. O.P.C.M. n. 3790 (2009) Urgent interventions to deal with seismic events occurred in the Abruzzo region on April 6. 2009 and other urgent civil protection provisions. (In Italian). (In Italian). O.P.C.M. n. 3790 del 9 luglio - " Ulteriori interventi urgenti diretti a fronteggiare gli eventi sismici verificatisi nella regione Abruzzo il giorno 6 aprile 2009 e altre disposizioni urgenti di protezione civile'. Pubblicata nella Gazzetta Ufficiale n. 166 del 20 luglio 2009.

42. Ordinance of the President of the Council of Ministers. O.P.C.M. n. 3881. (2010) Urgent interventions to deal with seismic events occurred in the Abruzzo region on April 6. 2009 and other urgent civil protection provisions. (In Italian). O.P.C.M. n. 3881 del 11 giugno 2010 - "Ulteriori interventi urgenti diretti a fronteggiare gli eventi sismici verificatisi nella regione Abruzzo il giorno 6 aprile 2009 e altre disposizioni urgenti di protezione civile". Pubblicata nella Gazzetta Ufficiale n.142 del 24 giugno 2010.

43. Dolce, M., and Manfredi, G., (2015). Libro bianco sulla ricostruzione privata fuori dai centri storici nei comuni colpiti dal sisma dell'Abruzzo del 6 Aprile 2009, Doppiavoce Edizioni (in Italian)

44. Grunthal, G.,1998. European Macroseismic Scale, Chaiers du Centre Européen de Géody-namique et de Séismologie, 15 Luxembourg.

45. Dolce M., Speranza E., Bocchi F., Conte C., Giordano F., Borzi B., Faravelli M., Di Meo A., Pascale V., 2019. Observed damage database of past Italian earthquakes: the Da.D.O. WebGIS. Bollettino di Geofisica Teorica ed Applicata, 60(2), 141-164.

46. Resolution Regional Council no. 615 - Abruzzi Region, August 9, 2010 - "Cost limits updating for residential subsidized housing" (In Italian) DELIBERAZIONE GIUNTA REGIONE ABRUZZO 9 AGOSTO 2010, DGR no. 6159 Agosto 2010 - "Aggiornamento dei limiti di costo per gli interventi di edilizia residenziale sovvenzionata e agevolata - Determinazioni regionali"

47. Zucconi M., Ferlito R., Sorrentino L., 2018. Simplified survey form of unreinforced masonry buildings calibrated on data from the 2009 L'Aquila earthquake, Bulletin of Earthquake Engineering, 16(7), 28772911.

48. Dolce, M. 2010a. Gestione dell?Emergenza e del post-emergenza. In L'Aquila. Il Progetto C.A.S.E. Complessi Antisismici Sostenibili ed Ecocompatibili, ed. R. Turino, 43-54. Pavia: IUSS Press.

49. DPC - Department of Civil Protection - Presidency of the Council of Ministers. 2018a. Dossier Case?Complessi Antisismici Sostenibili ed Ecocompatibili. Accessed December 04, 2018. <http://www.protezionecivile.gov.it/jcms/it/view_dossier.wp;jsessionid=5B1DF4BD76E2450B7AE0F D4481D82812.worker3?contentId=DOS274> (in Italian). 
50. DPC - Department of Civil Protection - Presidency of the Council of Ministers. 2018b. Dossier Map?Moduli Abitativi Provvisori. Accessed December 04, 2018. <http://www.protezionecivile.gov.it/jcms/it/view_dossier.wp?contentId=DOS322> (in Italian).

51. Welch DP, Sullivan TJ and Calvi GM (2012) Developing Direct Displacement Based Design and Assessment Procedures for Performance Based Earthquake Engineering. Pavia: Iuss Press.

52. ATC 58 (2012a) Seismic Performance Assessment of Buildings: Volume 1 (Methodology). Redwood City, CA: ATC.

53. ATC 58 (2012b) Seismic Performance Assessment of Buildings: Volume 2 (Implementation). Redwood City, CA: ATC.

54. Haselton CB and Baker JW (2018) SP3. Chico, CA: Haselton Baker Risk Group.

55. Del Gaudio C, De Risi MT, Ricci P, et al. (2018) Empirical drift-fragility functions and loss estimation for infills in reinforced concrete frames under seismic loading. Bulletin of Earthquake Engineering 17: $1285-1330$. 